\title{
DESIGN OF MECHANISM AND MOTION SYSTEM ON TANK PROTOTYPE USING ODOMETRY
}

\author{
Abdul Rahman, Mohammad Zaenal Arifin, Gesit Pratiknyo, Bagus Irawan. \\ Indonesian Naval Technology College, STTAL \\ Bumimoro-Moro Krembangan, Surabaya, 60178, Indonesia
}

\begin{abstract}
At present, Indonesia's defense forces are not yet on par with European countries. The size is the variation of Indonesia's defense equipment technology that has not been able to keep up with the defense equipment of European countries. Utilization of unmanned tank rides is a solution in empowering mobile combat equipment as a means of national defense and defense. Unarmed armored tank defense equipment as a means of national defense and defense. The Odometry technique applied in this study uses an encoder sensor device mounted on the two right and left wheels of the prototype tank. Wheel movement will produce the number of turns that can be calculated using an encoder sensor. the authors use odometry techniques aimed at estimating distances to destinations within a relatively small measurement area, in the wider measuring area this study uses GPS. Another goal is to get the accuracy and accuracy of distance measurements against the destination location. The results obtained in this study are the level of accuracy of the measurement of distance traveled in units of $\mathrm{cm}$ from the results of testing and implementation of the odometry system. The application of odometry is used to get the calculation of the change in distance due to the displacement of the prototype location during the autopilot motion process in relation to getting the accuracy of moving the position towards the waypoint. The measurement error rate obtained is less than $1 \%$. It is expected that this system can be used as a motion mechanism system on alutsi s ta tank.
\end{abstract}

Keywords : Odometri, Encoder, Waypoint, Autopilot

\section{INTRODUCTION}

\subsection{Background}

To realize state technology with sophisticated technology, it really needs some aspects to support such as dignified politics, economy that can fulfill basic needs, and defense capability that can protect national sovereignty.

At present, Indonesia's defense forces are not yet on par with countries in Asia. The size is the variation of Indonesia's defense equipment technology can compensate for European countries' defense equipment.

In a news report from the Telegraph, Thursday, March 22, 2018, China conducted a test of unmanned tanks and was broadcast by the Chinese state television station, CCTV. A Type 59 tank is running wirelessly controlled by a soldier. The device is a console with a screen and steering wheel. The implementation of the unmanned tank control system was made by the PLA Unmanned Combat System Laboratory. They are also building a control system of warships, aircraft and unmanned fighter jets.
Utilization of unmanned tank rides like the Chinese government does is a solution in empowering mobile defense equipment as a means of national defense and defense. Based on developing the defense and resilience pattern of the Republic of Indonesia, the author tries to raise it to be a research theme with the research title Design of Mechanism and Motion Systems in Prototype Tanks Using Odometry.

Odometry is, a use of data applied to the movement of the wheel to estimate changes in position over time, from the starting point to the next point. Odometry applied in this study uses a tachometer sensor device mounted on the two right and left wheels of the prototype tank. Wheel movement will produce the number of turns that can be calculated using an encoder sensor. The number of turns can be converted to the unit of distance in $\mathrm{cm}$. In this study the authors used the odometry technique aimed to estimate the distance to the destination in a relatively small measurement area, in a wider distance measurement area this study uses GPS. Another goal is to get the accuracy and accuracy of the distance measurement to the destination, considering that GPS has a considerable measurement error in the range of 
meters. So that in this study the use of odometry is expected to be able to help prototype tanks to the destination location more accurately.

\subsection{Problem Formulation}

In this study, it is necessary to formulate problems in building the Mechanism and Motion system design in Prototype Tanks using Odometry. Some of these problems are:

a. How to design a tankless drive propulsion system?

b. How to design a prototype tank displacement position calculation system using Odometry?

\subsection{Research Objectives}

The objectives of this research are:

a. Designing tank drive systems without

b. Designing a system for calculating the movement of prototype tank positions using Odometry.

\subsection{Research Benefits}

The benefits of the design of the Mechanism and Motion system in Prototype Tanks Using Odometry in this study are:

a. As a defense equipment for the Navy without involving personnel in the Alutsista tank.

b. As an Indonesian Armed Forces defense weapon that can be controlled remotely.

c. Reducing Personnel Losses.

\section{LITERATURE REVIEW}

\subsection{Data Communication}

Manipulators are often called the base frame and the tip of the manipulator is usually equipped with an end effector, one of which is a gripper. For details, a manipulator schematic is shown in Figure 2.1.

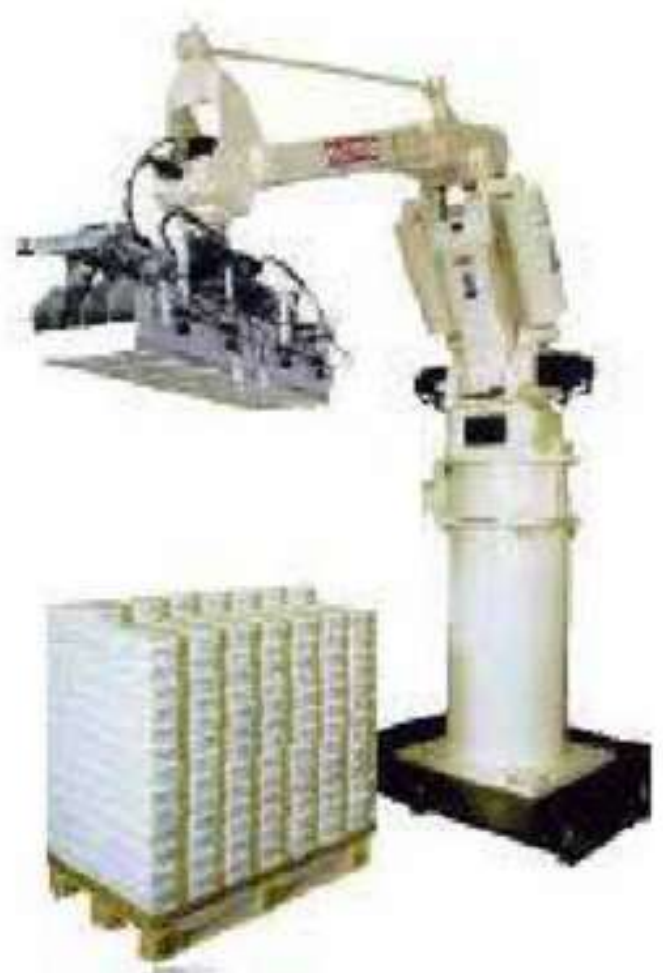

Figure 2. 1 Robot Manipulator

(Source: http://www.eprints.undips.ac.id.com )

\subsection{Mobile Robot}

Mobile robot is a robot that can move freely because it has a means of movement to move positions. All this is adjusted to the terrain to be traversed and also by the tasks given to the robot. Here is the classification of robots according to locomotion type.

The wheels are often chosen, because they provide good traction, are easy to obtain and use, and are also easy to attach to robots. Traction is a variable of the wheel material and the surface crossed by the wheel. For example two-wheeled, fourwheeled, six-wheeled or caterpillar (tanktreaded) wheeled which can be seen in Figure 2.2.
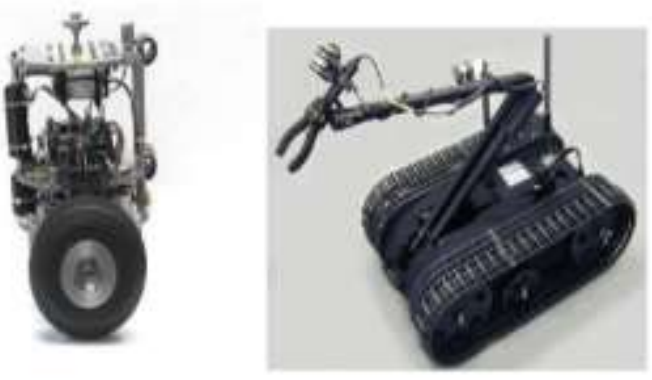

Figure 2. 2 Two-wheeled robot (a) and a

Caterpillar wheeled robot (b)

(Source: http: www.eprints.undips.ac.id.com) 


\subsection{Stepper Motor}

Stepper motor is a DC motor that specifically rotates in a fixed degree called a step (step). One step between 0.9 to 90 . Stepper motors consist of rotors and stators. The rotor is permanently maget while the stator is an electromagnet. The rotor will move if the stator is given electricity. This electric current generates a magnetic field and makes the rotor adjust to its magnetic poles.

This can be done by counting the number of steps that must be given from the reference position. The size of the step is determined by the number of rotors and stator poles. There is no cumulative error ie the angle error does not continue to increase with increasing step.

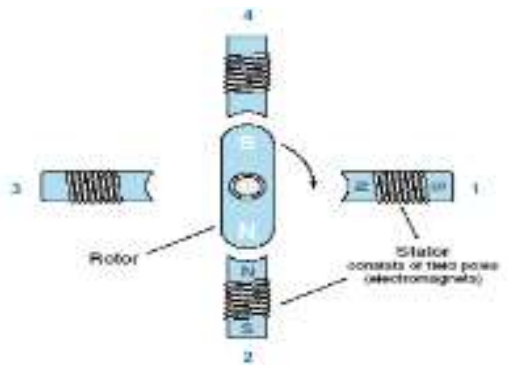

Figure 2. 3 Figure Stepper Motor

(Source: Self-processed Results)

Stepper motors work in open loop, ie the regulator sends a number of steps to the motor to move the rotor to the desired position. For example stepper motors on a floppy disk drive .

In open loop work, the stepper motor should move one step at a time, but if the load is too excessive, the stepper motor has torque to make one step. Maybe the rotor will spin a little and then return to its original position without reaching one step. This is called stalled. This event is depicted in Figure 2.4. In practice the rotor will stop before it is right in front of the stator when the weakening step torque is the same as the load torque.

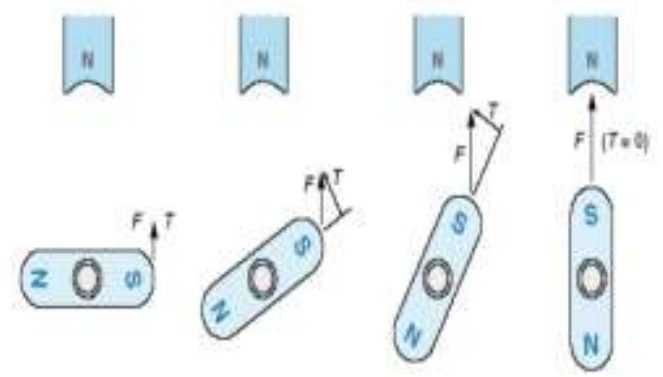

Figure 2. 4 Changes in force and torque when rotor

(Source: Self-processed Results)
For example the rotor is desired to rotate counter-clockwise. If the rotor is left one step (step) from the stator that is when the rotor just wants to move the second coil has already been flowed Figure 2.4. This causes the rotor to rotate counter-clockwise but can also be clockwise in pursuit of the stator's north pole. Because it is limited so that the rotor does not remain more than half a step.

At this time the torque of the motor will be enough to rotate the rotor in the desired direction without having to stall. When the motor rotates quickly, the step of the motor will remain in the presence of moisture from the rotor.

\subsection{Motor ( Direct Current )}

DC motor ( Direct Current) is a basic electromechanical equipment that functions to convert electric power into mechanical power. By giving a voltage difference to the two terminals, the motor will rotate in one direction, and if the polarity of the voltage is reversed then the direction of rotation of the motor will be reversed too. Figure 2.5 is an example of a DC motor used as a conveyor drive.

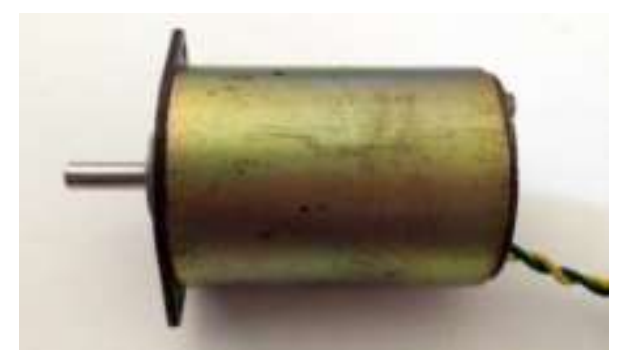

Figure 2. 5 Image of a DC Motor (Source: http://www.elektronikadasar.web.id.com)

\subsection{Motor Drivers}

L293 and L298 are examples of ICs that can be used as DC motor drivers. This IC uses the $\mathrm{H}$-Bridge working principle . Each $\mathrm{H}$ - Bridge is controlled using TTL voltage levels originating

from the microcontroller output. L293 can control 4 DC motors while L298 can control 2 DC motors. The voltage that can be used to control the robot can reach $46 \mathrm{Vdc}$ and the current reaches $2 \mathrm{~A}$ for each channel.

The speed regulation of the two motors is done by controlling the duration of the active pulse (PWM - Pulse Width Modulation method ) which is sent to the motor driver circuit by a controller module (Basic Stamp microcontroller ).

The PWM duty cycle that is sent determines the rotational speed of the DC 
motor. Figure 2.6 shows the L293 and L298 Multiwatt $15 \mathrm{ICs}$ used as motor drivers.
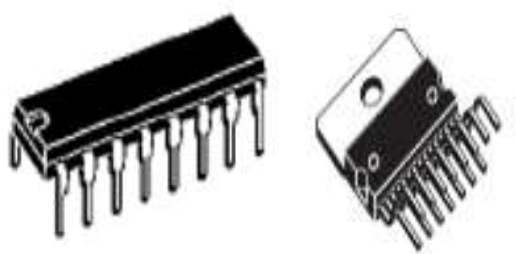

Figure 2. 6 ICs L293 and L298

(Source: $h$ ttp://www.selectronic.fr/includes_sel ectronic/pdf/Thomson/L298.pdf)

\subsection{Motor Control}

MMBE (Motor Mind B enhanced) is a DC motor control component that has the ability to control one DC motor. Where in it integrated control system PI ( Proportional Intergral).

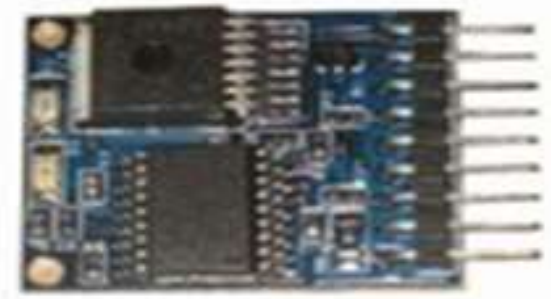

Figure 2. 7 Enhanced Main B Motor ( Source: http: //www.solutions- cubed. com / solutionscubed / ProductsPage /

Downloads / MMBe_DS_1.PDF)

\section{Features of MMBE:}

a. Maximum Current 1.75 A (6A Peak) Voltage Between 6-36 VDC.

b. The frequency of PWM is $242 \mathrm{~Hz}$ or $15.5 \mathrm{KHz}$.

c. Serial Interface TTL 2.4KBPS or 9.6KBPS.

d. $0-65,535 \mathrm{~Hz}$ tachometer.

e. Integreted Proportional Closed speed control. Can easily access EEPROM .

\subsection{Odometry}

Odometry is a use of data from the movement of the wheel to estimate changes in position over time and also from the starting point to the next point. Odometry is used to estimate position relative to initial position. To estimate the relative position of the robot, a calculation of the number of pulses generated by the rotary encoder sensor per unit of measure is then converted to millimeters.

Equation:

$$
\begin{aligned}
& \text { Pos } x=\text { jarak } x \operatorname{Cos}(\varnothing) \\
& \text { Pos } y=\text { jarak } x \operatorname{Sin}(\varnothing)
\end{aligned}
$$

To determine the direction of the robot's error toward the destination point, the phytagorean theorem is used which will produce the current position (path) and the distance to the destination point, following the calculation:

target_distance $=\sqrt{\mathrm{x} 2}$

$$
\begin{aligned}
\mathrm{x} & =\mathrm{X}_{-} \text {tujuan }-\mathrm{Xpos} \\
\mathrm{y}= & Y_{-} \text {tujuan- } \mathrm{Ypos} \\
& =\sqrt{\mathrm{x} 2} \\
& +\mathrm{y} 2
\end{aligned}
$$

Headings of known robots so that we can count.

\subsection{Rotary Encoder}

Rotary encoder is an electromechanical device that can monitor movement and position. Rotary encoder is generally used in controlling robots, motor drives, etc. The rotary encoder is composed of a thin disk which has holes in the circle of the disc. LEDs are placed on one side of the disk so that the light will go to the disk.

\subsection{Arduino Microcontroller}

Arduino is said to be a platform of physical computing that

is open source. First of all it needs to be understood that the word " platform " here is an appropriate choice of words. Arduino is not just a development tool, but it is a combination of sophisticated hardware, programming languages and Integrated Development Environment (IDE).

IDE is a piece of software that is very instrumental in writing programs, compiling it into binary code and uploading it into the microcontroller memory. In addition, there are also many supporting modules (sensors, displays, drives and so on) made by other parties to be connected to Arduino. In Figure 2.8 the Arduino Mega 2560 Board.

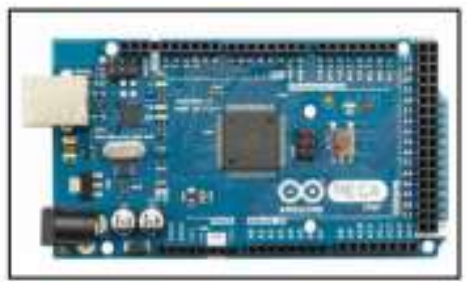

Figure 2. 8 Arduino Mega 2560 Board ( Source: www.arduino.cc/en/Products/Counte rfeit, 2014)

I $2 \mathrm{C}$ is a two-way serial communication standard using two channels specifically designed for IC control. Devices connected to the I 2C bus system can be operated as Master and Slave .

The Master is a device that starts data transfer on the I 2C Bus by forming 
a Start signal, ending the data transfer by forming a Stop signal, and generating a clock signal. Slave is a device that is mastered by the ma

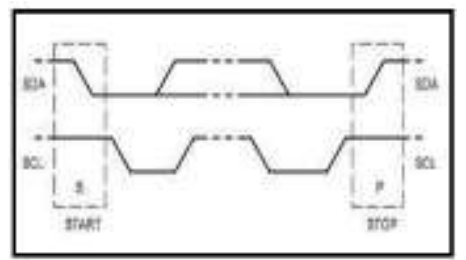

Figure 2. 9 Start Stop Signal Conditions (Source: https://purnomosejati.wordpress.com )

Data transmission between devices occurs after the start sequence and before the stop sequence. Data that is transmitted in a number of 8 bits with MSB (Most Significant Bit) is sent first to LSB (Least Significant Bit) then there is always an additional one bit which is an Acknowledgment (ACK) bit.

The ACK bit is used to determine the condition of data transmission, if the ACK bit is a low condition then the existing device has received data and is ready to receive further data.

\section{RESEARCH METHOD}

\subsection{Research Design}

The research that will be carried out is applied research, where this research aims to apply the sciences in the field of mechanism and DC stepper motor drive system to become a prototype tank in the form of miniature intended for the purpose of being an unmanned vehicle. In the Design of Mechanisms and Motion Systems in Prototype Tanks Using Odometry, the author will translate the design of the driving mechanism into the real form of a prototype tank, which is expected to carry out missions or operations in the field.

\subsection{Research Procedure}

In the procedure of this proposal will be discussed about the time and place of research as well as the tools and materials that will be used in making the design of Mechanisms and Motion systems in Prototype Tanks using Odometry, then design, collect data and process data.

\subsection{Time and Place}

The research location is a place or area where the research will be conducted. The research conducted by the author took place on the Moro Krembangan STTAL Campus in
Surabaya. The time used in this study began in July 2019 until the end of December 2019.

\subsection{Tools and Materials}

Tools that will be used in the research and design of this final project include:
a. Computer / Laptop
b. 2 Stepper Motor Units
c. 2 Motor Driver Units
d. 1 Acrylic Meter
e. 1 set of Tank Wheels and Chain
f. 1 AVOmeter
g. 1 set of toolset

\subsection{Research Design}

Study design of mechanism $d$ and System Motion p No Prototype Tank Men NOTICE Odometri applying research stages, as:

\section{a. Preliminary studies}

Preliminary studies are study processes to obtain information about the research to be conducted.

b. Problem analysis

Problem analysis is a study to find out the causes of problems, as well as alternative solutions and later solutions to problem solving

c. Need analysis

Requirement analysis is part of the process of software requirements that play a role in bridging the gap that often occurs between the level of engineering needs and software design. (Pressman, 2008)

\section{d. Design analysis}

Is the process of selecting tools to analyze data, so that the formulation of the problem can be solved and the objectives can be proven. At this stage the writer must choose a data analysis tool that matches the data to be obtained in the field study.

\section{e. Design.}

This design will discuss the analysis and discussion of the prototype tank motion system. A prototype motor-based tank motion system with a 1.8 degree resolution for every 1 step. 
$P$ roses design body driving mechanism tanks as well as the development steps contained in Figure 3.1.

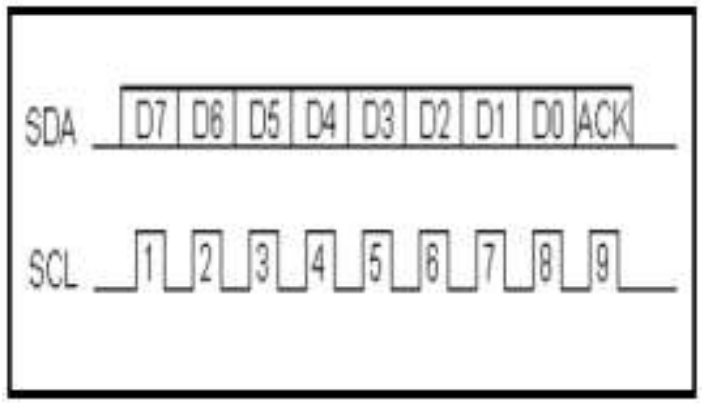

Figure 3. 1 Research Flow (Source: Self-processed Results)

\subsection{System Design}

In the study of design of Mechanisms and Motion Systems in Prototype Tanks Using Odometry, the author focuses more research on body mechanisms, driving mechanisms and driving drivers. This relates to the tank's motion system in carrying out the mission.

In general, the design of building mechanisms and motion systems in Prototype Tanks using Odometry can be explained as follows:

a. Designing and making tank rides using $5 \mathrm{~mm}$ acrylic.

b. Apply tank wheels that have been integrated with dc motors and gearboxes to the tank body. 4 wheels are used.

c. Making a dc motor speed reading system using a rotary encoder, as well as stabilizing the speed of each motor drive to be uniform according to the needs of the Arduino Mega.

d. Estimating the location of tank rides using odometry, mapping the location of $x$, $y$ using the tank wheel rotation mechanism which originates from the reading of the number of tank wheels through the encoder rotary.

Next Figure 3.2 block diagram of the Motion System Mechanism in Prototype Tanks Using Odometry.

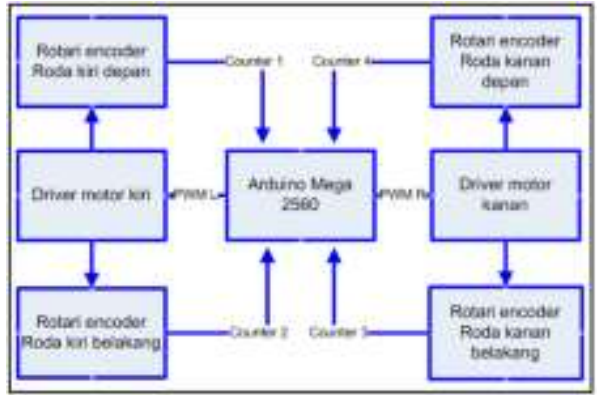

Figure 3.2 Tank Motion System

(Source: Self-processed Results)

\subsection{Data Collection}

In the Design of Mechanisms and Motion Systems in Prototype Tanks Using Odometry, the author uses several 3 data collection methods. Data collection methods Design Mechanisms and Motion Systems on Prototype Tanks Using Odometry that will be done by the author, namely:

a. Observation, this method is done by the writer to do research directly in the field.

b. Interview, this method is carried out by way of question and answer to competent parties regarding defense equipment tanks.

c. Documentation, this method is done by collecting data from books, notes, and research results in relevant agencies regarding the Indonesian Navy defense equipment.

\subsection{Data Processing}

The data processing used in this final assignment research is a process by the author after obtaining some information collected in the data collection process. The data obtained will be reviewed and become a reference in the process of design analysis and system design.

Reference data collection is done by finding reference technical component data on the device to control the Prototype tank drive. Then make a drive control using Arduino software, after which it is assembled and carried out the testing tool.

\section{DESIGN, IMPLEMENTATION TESTING OF THE SYSTEM}

AND

\subsection{Research Design}

In this chapter the author will discuss the analysis and discussion of the prototype tank motion system. A prototype motor-based tank motion system with a 1.8 degree resolution for 
every 1 step. The analysis and discussion in this section are more likely to discuss the performance of the motion system based on the input of pulses in its task of converting to a mechanical motion system.

\subsection{Design of the Prototype Tank Mechanism Motion System}

The mechanical part is part of the real shape of the prototype tank, the main material for making this prototype tank is to use an acrylic base material with a thickness of $5 \mathrm{~mm}$. The steps of making a prototype tank mechanic is to determine the size of the prototype Autopilot tank to be made. Then make the size for length, width, and height according to the needs of the components that will be arranged later on the autopilot tank prototype tool

In designing the motion system, the writer uses two stepper motors which are installed as a left and right driving motor. The choice of stepper motor is due to the large enough torque and its ability to maintain a fairly stable motor rotation. Control of speed and number of revolutions on a stepper motor can be done by adjusting the pulse and frequency. Frequency is involved in speed regulation, while the number of pulses involved in setting the number of turns or rotation desired.

In the design of the motion system, the author uses the L298N motor driver. L298N Hbridge is a dual motor control module $2 \mathrm{~A}$ which can be integrated with Arduino. The module can be used to control the speed and direction of a bipolar stepper motor.

The L298N H-bridge module can be used in a working voltage range of 5 to $35 \mathrm{~V}$ DC. There is a $5 \mathrm{~V}$ regulator that is onboard. For more details about the L298N motor driver used by the author in this engineering design, can be seen in Figure 4.1 below.

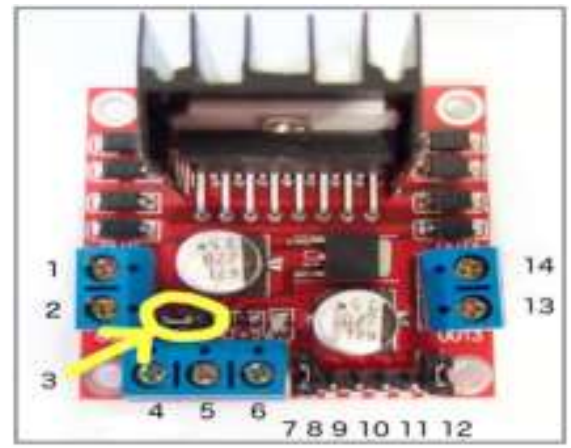

Figure 4.1 L298N Motor Driver (Source: Self-processed Results)
The description of the use of the L298N motor driver pin with Arduino Mega 2560 can be explained as follows:

a. DC motor 1 "+" or A + stepper motor

b. DC motor 1 "-" or A-stepper motor

c. 12V jumper - remove this if using a supply voltage greater than $12 \mathrm{~V}$ DC. Jumper to activate the onboard $5 \mathrm{~V}$ regulator

d. A 7.2VDC battery supply voltage is connected

e. GND

f. Output 5V if $12 \mathrm{~V}$ jumpers are activated can be used for additional $5 \mathrm{~V}$ power sources

g. DC motor 1 jumper enable. Used to activate the motor 1 .

h. IN1 is connected with Arduino Mega pin 22

i. IN2 is connected with Arduino Mega pin 24

j. IN3 is connected with Arduino Mega pin 26

k. IN4 is connected with Arduino Mega pin 28

I. DC motor 2 jumpers enable. Used to activate the motor 2 .

m. DC motor 2 "+" or stepper motor B $+$

n. DC motor 2 "-" or stepper motor B-

For more details about the L298N driver module diagram scheme can be seen in Figure 4.2 below.

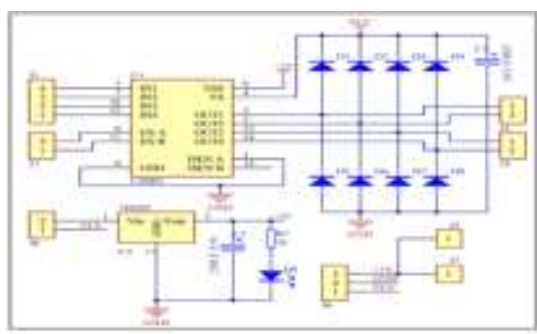

Figure 4.2 Schematic Motor Driver L298N

(Source: Self-processed Results) 


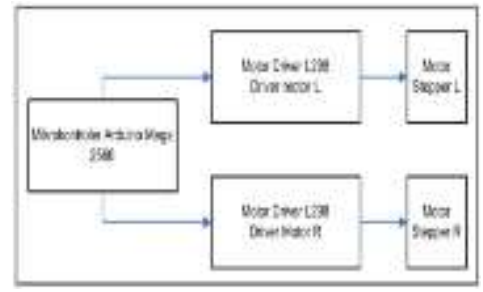

Figure 4.3 Block Diagram of a Stepper Motor System

(Source: Self-processed Results)

The block diagram in Figure 4.3 can be illustrated in the form of a more detailed cabling relationship in Figure 4.4 below.

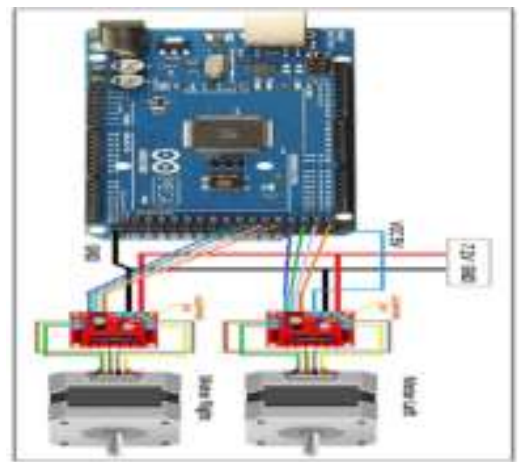

Figure 4.4 Relationship of Stepper Motor

Cabling with Arduino Mega 2560

(Source: Self-processed Results)

In the design of Odometry in this design research, the authors plan to estimate the position of the prototype tank with changes in position over time using constants:

$(x, y, \theta)=$ estimated position of the prototype tank

$\varphi \mathrm{R}, \varphi \mathrm{L}=$ right and left wheel rotation

To get an odometry value, the encoder value must be done through 2 conversions:

a. Changes in the number of encoders to changes in wheel position;

b. Change the position of the wheels to change the position of the prototype tank

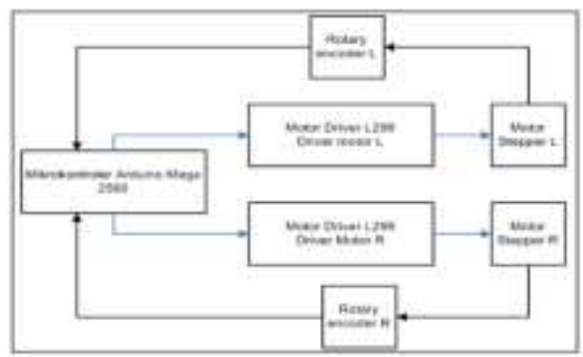

Figure 4.5 Odometry System Block Diagram (Source: Self-processed Results)

\subsection{Implementation}

To implement the prototype tank mechanical motion control system, the authors configure the I / O pins that are used to drive the motor driver. Arduino Mega 2560 pins that are used for driving the L298N motor driver, namely:

a. Pin 22 is used as a stepper motor control L pin A, connected to the L298N motor driver pin 8

b. Pin 24 is used as the stepper motor control L pin B, connected to the L298N motor driver pin 9

c. Pin 26 is used as a stepper motor control L pin C, connected to the L298N motor driver pin 10

d. Pin 28 is used as the stepper motor control L pin D, connected to the L298N motor driver pin 11

e. Pin 30 is used as an R step A stepper motor control, connected to the L298N motor driver pin 8

f. Pin 32 is used as a stepper motor control R pin A, connected to the L298N motor driver pin 9

g. Pin 34 is used as a stepper motor control R pin A, connected to the L298N motor driver pin 10

h. Pin 36 is used as a stepper motor control R pin A, connected to the L298N motor driver pin 11

i. Pin 2 is used as $L$ encoder input

j. Pin 3 is used as $R$ encoder input

The stages in the implementation of the distance calculation system using odometry techniques can be explained as follows:

a. Count the number of pulses per rotation generated by the left and right motors.

b. Calculate the resulting displacement due to displacement of the prototype tank position.

To calculate the number of pulses per rotation, it can be done by counting the number of pulses generated by Arduino to drive a stepper motor driver. The number of pulses with a fixed loop is fixed because it adjusts to the parameters or specifications of the motor as many as 200 pulses per rotation. By counting or 
adding pulses per rotation, a total number of pulses will be obtained when the motor rotates at a certain time interval. By dividing the number of pulses with the puls calibration results into $\mathrm{cm}$, the resulting mileage will be obtained.

To get an overview of the distance calculation process can be explained in Figure 4.6 below.

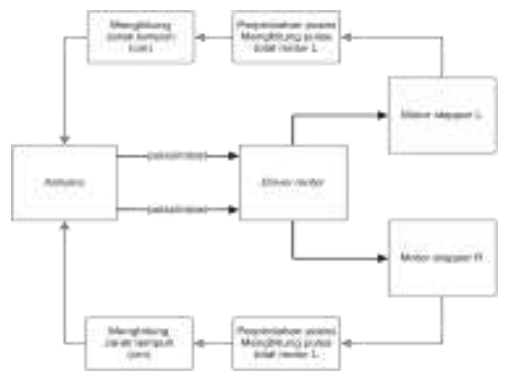

Figure 4.6 Position Displacement Calculation System

(Source: Self-processed Results)

The distance measurement process as shown in Figure 4.6, is applied to the autopilot control process to replace the prototype motion process when it goes to the waypoint point within a specified area or radius.

The process of prototype tanks to the waypoint using odometry to replace GPS sensors, can be explained as follows:

a. Identify if the location of the prototype tank has entered the waypoint radius.

b. Calculate the total left and right motor pulses

c. Convert the number of pulses to distance

d. If the prototype distance is more than 0 , do processes 2,3 and 4

e. If the prototype distance is equal to 0 , then the prototype proceeds to the next waypoint using GPS.

\subsection{Testing}

Testing of this study was carried out to obtain the expected data. Some of them are testing data reception. Testing the receipt of data from what is displayed through the monitor screen and the results of the image after several tests

\subsection{Purpose of Sending Data}

To test the stepper motor, the writer connects the Arduino Mega 2560 pin with the stepper motor driver as shown in Figure 4.7 below. And connecting the motor driver with a stepper motor is shown in Figure 4.7.

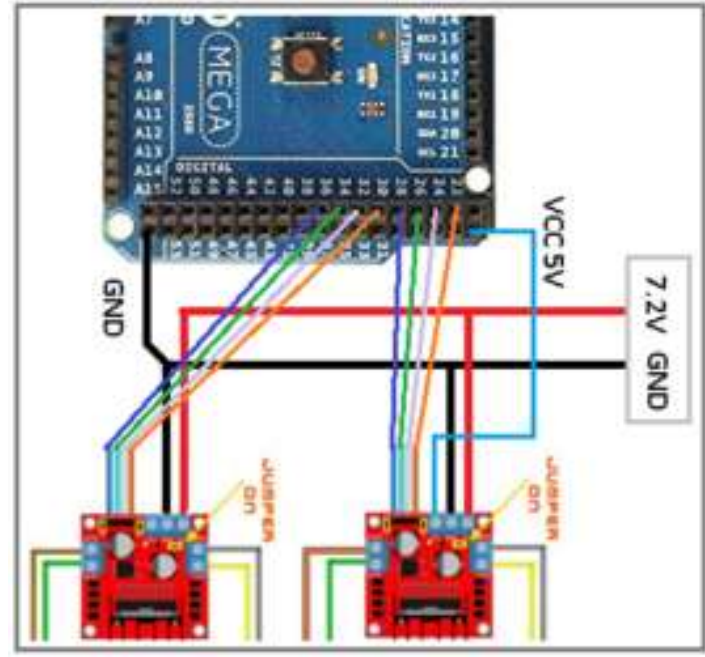

Figure 4. 7 Arduino Mega Wiring Relations With the L298 Motorcycle Driver (Source: Self-processed Results)

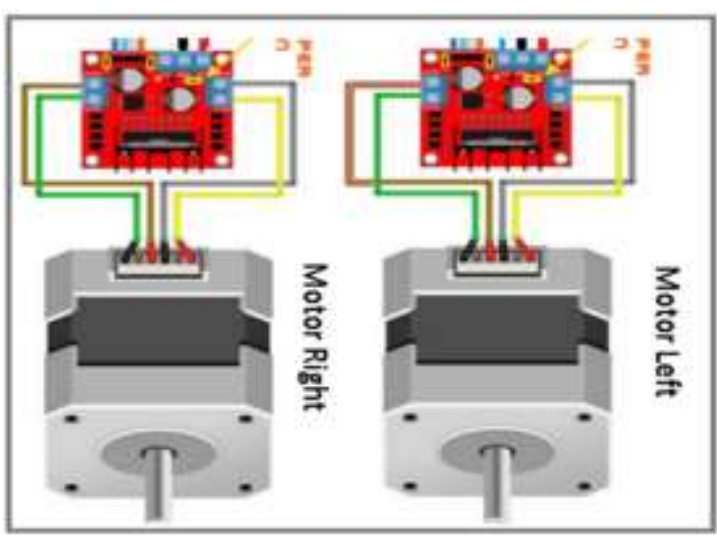

Figure 4. 8 Relationship of W298 Motor Driver Cabling with Stepper Motor

(Source: Self-processed Results)

In this test the authors do not use the stepper motor program library, but the authors write their own program code. The program code in the control of this stepper motor, the author uses timer 0 , as a timer interval to generate pulses.

The following is the initial program code for initializing pins used for driving a stepper motor.

const int ML1 = 22;

const int ML2 = 24;

const int ML3 = 26;

const int ML4 = 28;

const int MR1 = 30;

const int MR2 = 32;

const int MR3 $=34$;

const int MR4 = 36; 


\section{pinModeFast(ML1, OUTPUT); pinModeFast(ML2, OUTPUT); pinModeFast(ML3, OUTPUT); pinModeFast(ML4, OUTPUT); pinModeFast(MR1, OUTPUT); pinModeFast(MR2, OUTPUT); pinModeFast(MR3, OUTPUT); pinModeFast(MR4, OUTPUT);}

For sequential pulses in stepper motor control can be seen in the function of the following program code.

$$
\begin{aligned}
& \text { void motorL_function() }\{\} \\
& \text { void motorR_function( })\{\}
\end{aligned}
$$

The functions of the $L$ motor and the $R$ motor the two motors can be explained as follows,

The motorL_function () and motorR_function () functions are run in the main loop program that will be repeated periodically. Determination of speed is done by adjusting the time interval on the generation of pulses, pulses generated by the number of sequences as much as 4 times.

Each sequence will be tasked to run the stepper motor differently.

The sequential formed is as follows:

$$
\begin{aligned}
& 1.1010=\text { pins } A \text { and } C \text { of } \\
& \text { the active stepper motor }
\end{aligned}
$$

2. $0110=$ pins $B$ and $C$ of the active stepper motor

3. $0101=$ pins $B$ and $D$ of the active stepper motor

4. $1001=$ pins $A$ and $D$ of the active stepper motor

The following program code for running a stepper motor based on each sequence.

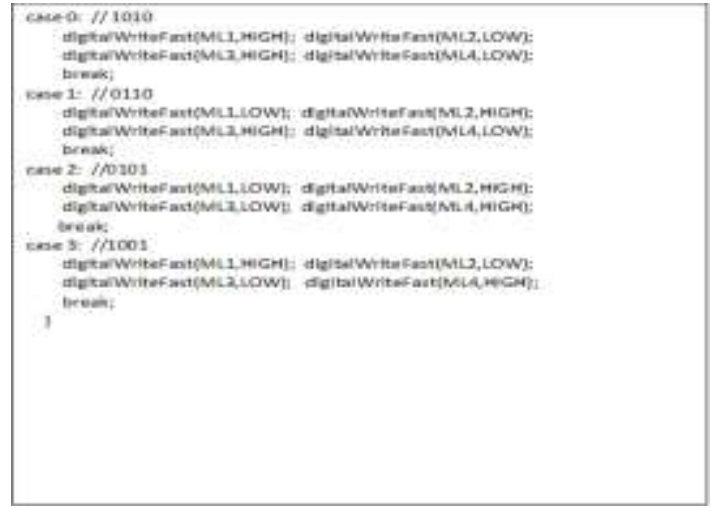

In Figure 4.9 is a picture of the motor mechanism, which is accompanied by a sign of a piece of paper affixed to the wheels, and also given an initial sign of starting the motor to spin. In this test the author tests the motor rotation to find out whether the motor can rotate properly back to the beginning. It is important to know the accuracy of the motor accuracy in turning 1,2,3 and 4 turns.

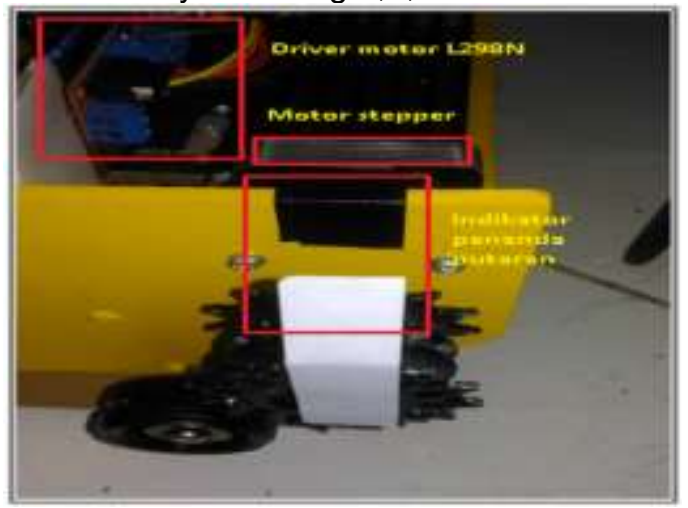

Figure 4. 9 Motor Rotational Testing (Source: Self-processed Results)

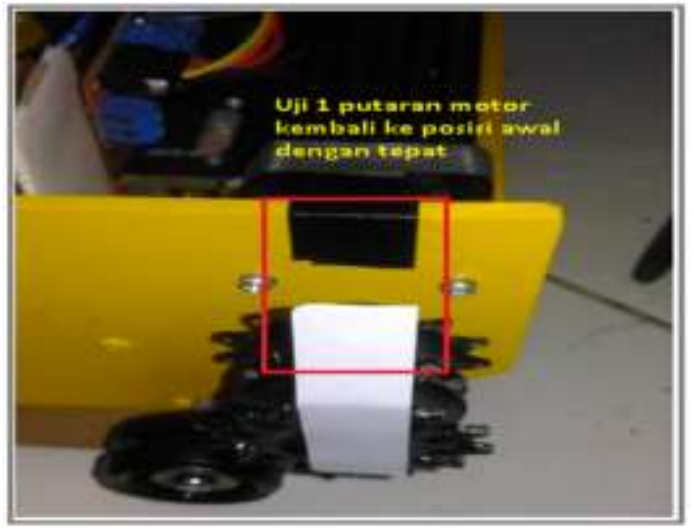

Figure 4. 10 Test Result Round Motor Stepper Into 1

(Source: Self-processed Results) 


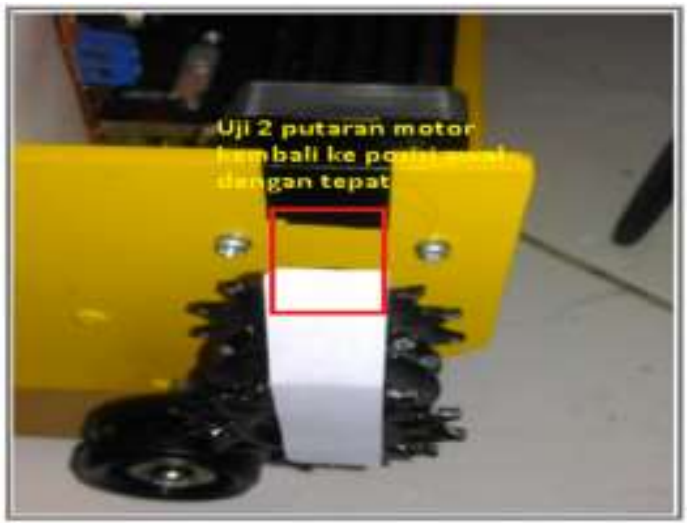

Figure 4. 11 Test Result Round Motor Stepper Into 2

(Source: Self-processed Results)

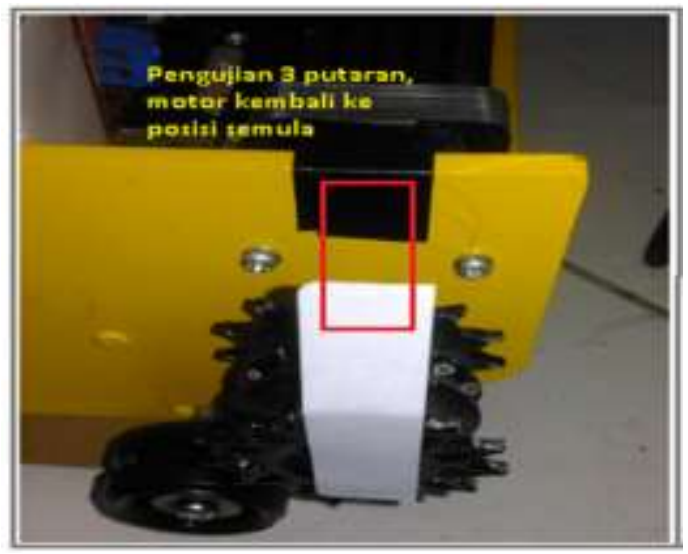

Figure 4. 12 Test Result Round Motor Stepper 3rd

(Source: Self-processed Results)

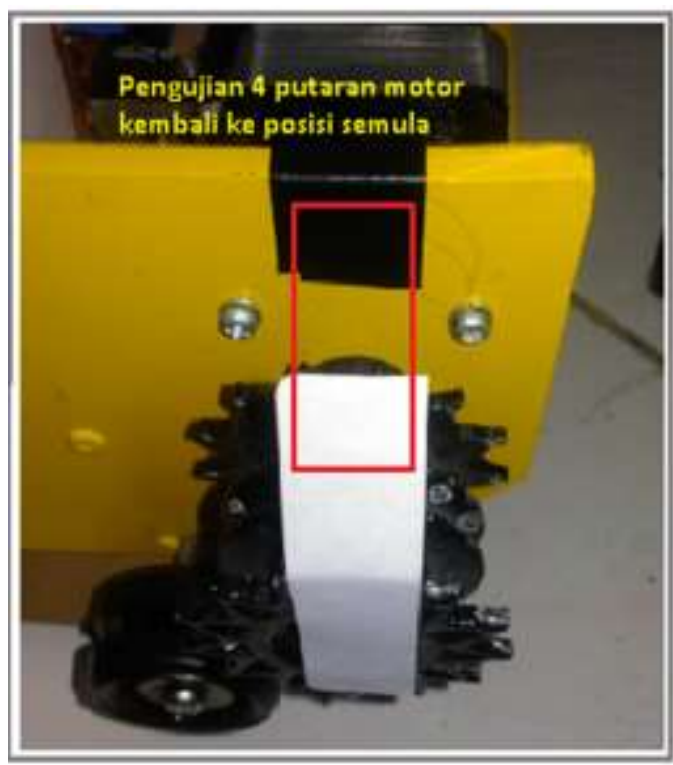

Figure 4. 13 Results of the 4th Stepper Motor Rotational Test (Source: Self-processed Results)
To run the motor rotation test function, the writer adds the following program code.

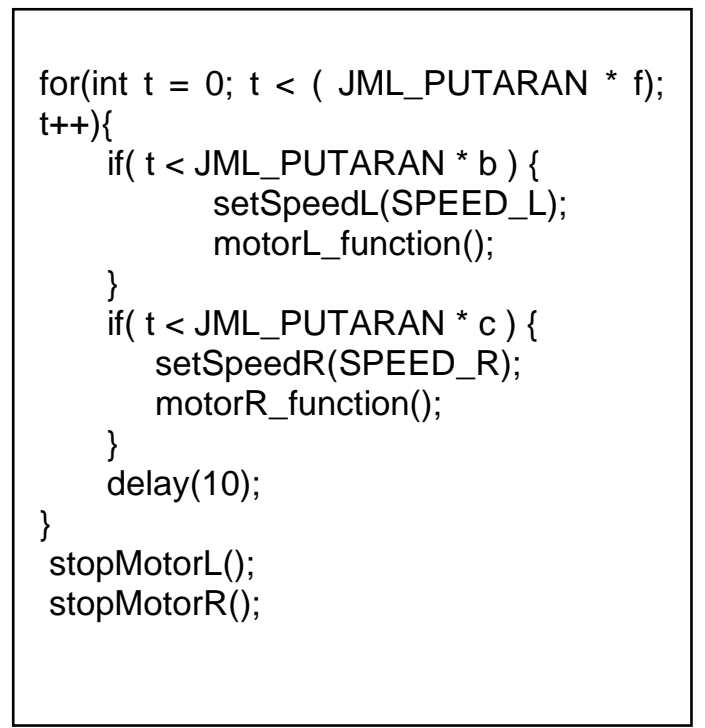

In the stepper motor rotation test program code, the program will perform a loop function to generate pulses as many times as the number of turns multiplied by the number of pulses per rotation, in this test the number of rotating pulses is 200 pulses. This relates to the technical data of motor resolution per pulse 1.8 degrees. Thus for one rotation of a 360 degree motor requires 200 pulses.

\subsection{Testing Mechanisms of Motion}

In this test the author will test, the distance of motion of the tank in units of $\mathrm{cm}$ based on the number of pulses provided. The pulses provided to the stepper motor driver will drive the stepper motor to move or spin. The movement of the prototype tank in the forward or backward direction will experience displacement, this displacement is measured using a meter to find out how far the prototype tank is moving. This transfer value will be used by the author to calculate the comparative value of the number of pulses with a distance in units of $\mathrm{cm}$. In testing the effect of wheel friction with the floor ignored, the coefficient of friction is considered 0 because this is a complex calculation, so the friction coefficient is considered a negligible factor error. Testing is done by giving pulses gradually per 10 steps. 1 step represents step $\mathrm{x}$ the stepper motor revolution. Figure 4.14 is a prototype tank test kit that has been assembled as a whole. 


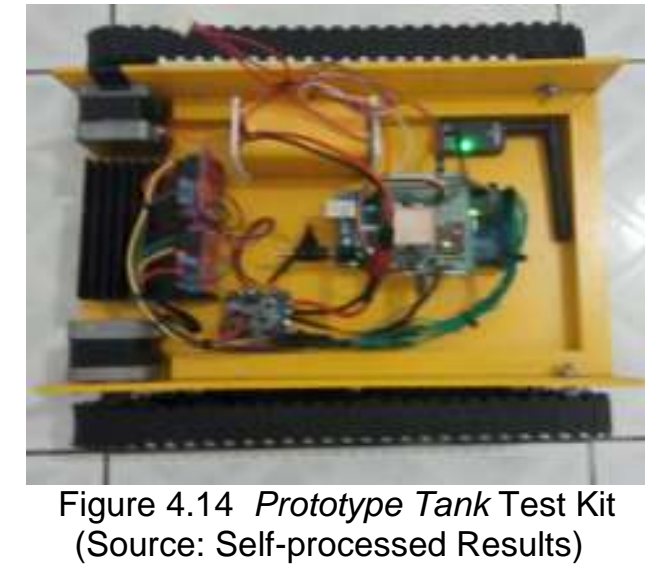

In this test will $d$ i present the test results as much as 10 times the test in the form of drawings testing with the results of distance measurement. In Figure 4.15 is a motion control program used for testing the mechanism of motion of a tank. This program is used to give orders for the number of rounds of tank wheels and the speed of tank motion.

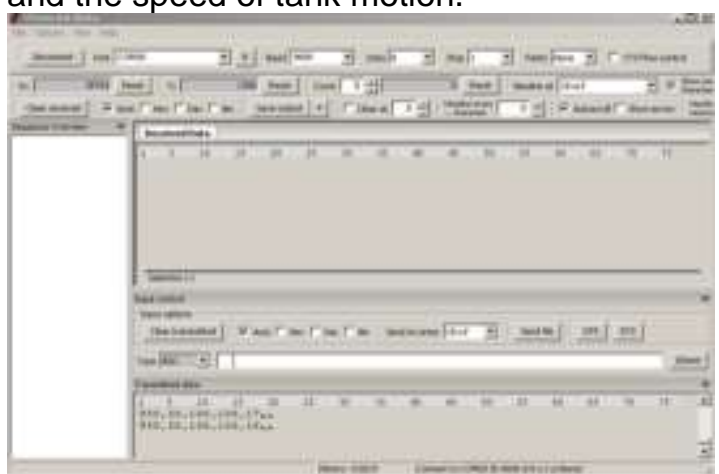

Figure 4.15 Motion Control Terminal Monitor

(Source: Self-processed Results)

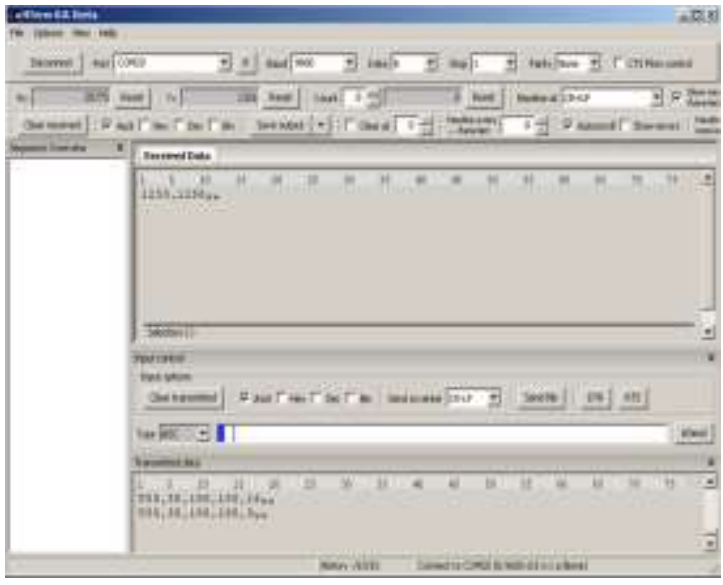

Figure 4.16 Measurement Results Number of Pulses at 5 Wheel Rotations (Source: Self-processed Results)
At the $G$ amber 4.17 and 4.18 following a motion tank test results presented in Figure beginnings tank position and the end position after position shift tanks in five rounds left and right wheels.

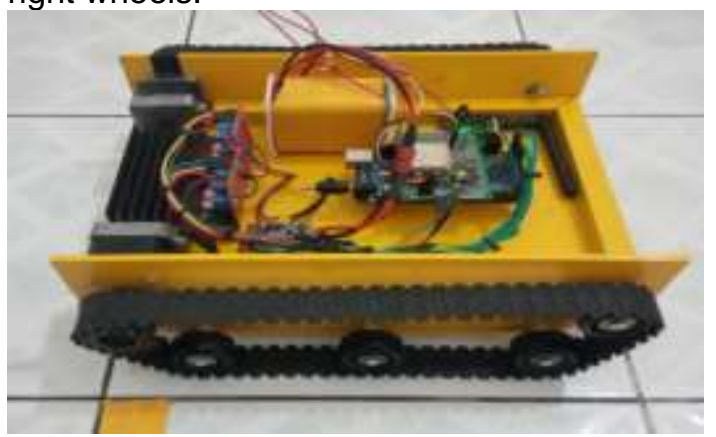

Figure 4. 17 Figure Prototype Tank in Initial Position

(Source: Self-processed Results)

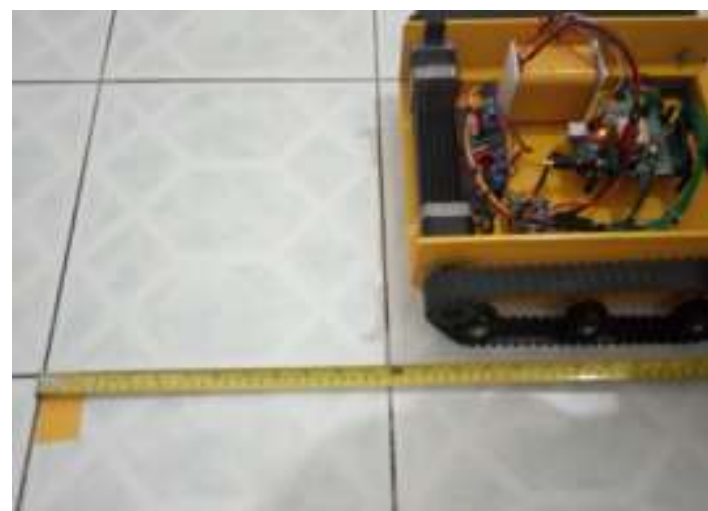

Figure 4.18 Figure Prototype Tank in Final Position

(Source: Self-processed Results)

From the measurement results obtained, the results of measurements of the distance of $32 \mathrm{~cm}$ and the number of pulses needed to reach a distance of $32 \mathrm{~cm}$ is 1250 pulses. In this test, if it is included in the formula for calculating the pulse to mileage ratio, the results of the comparison are as follows

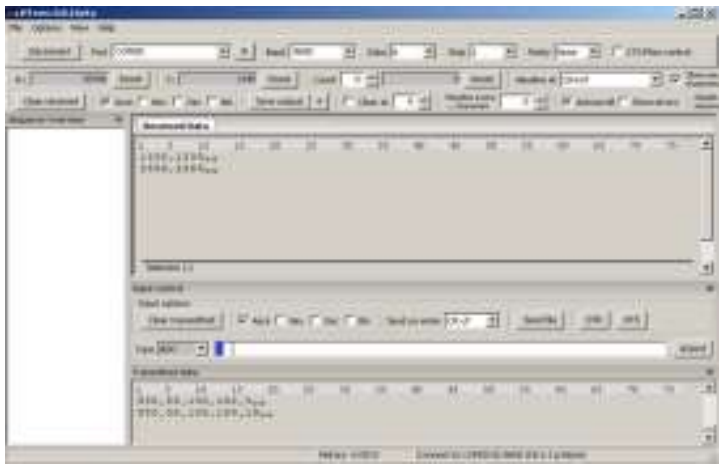

Figure 4.19 Results of Pulse Measurement at 10 Cycles

(Source: Self-processed Results) 
The results of testing the distance traveled by the number of wheel rotations given are presented in Figure 4.20. In Figure 4. 20 is to explain the initial position of the tank and the final position of the tank after moving with 10 rounds of the right wheel and left wheel.

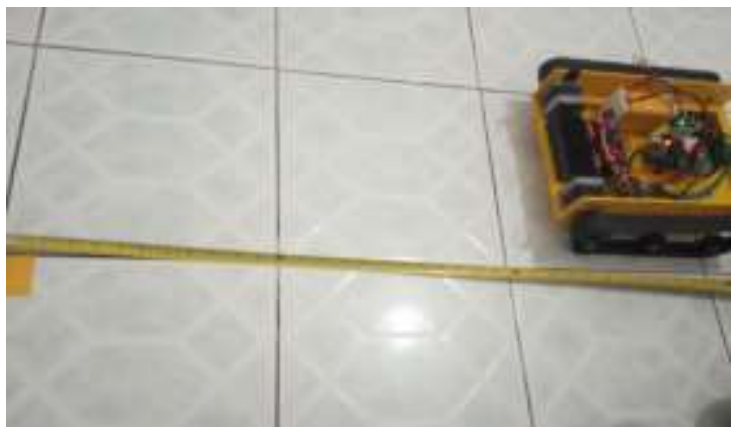

Figure 4.20 Figure of Prototype Tank in Final Position

(Source: Self-processed Results)

From the measurement results obtained, the results of measuring distance of $65 \mathrm{~cm}$ and the number of pulses needed to reach a distance of $65 \mathrm{~cm}$ is 2500 pulses. In this test, if it is included in the formula for calculating the pulse to mileage ratio, the results of the comparison are as follows

$$
\begin{aligned}
\text { pulsa per } \mathrm{cm} & =\frac{\text { pulsa }}{\text { jarak ukur }} \\
\text { pulsa per } \mathrm{cm} & =\frac{2500}{65} \\
\text { pulsa per } \mathrm{cm} & =38.46 \mathrm{pulsa} / \mathrm{cm}
\end{aligned}
$$

The third test the author gave the command 15 rounds of the right wheel and left wheel. In Figure 4.21 the following is the result of measurement of the number of pulses generated at 15 turns.

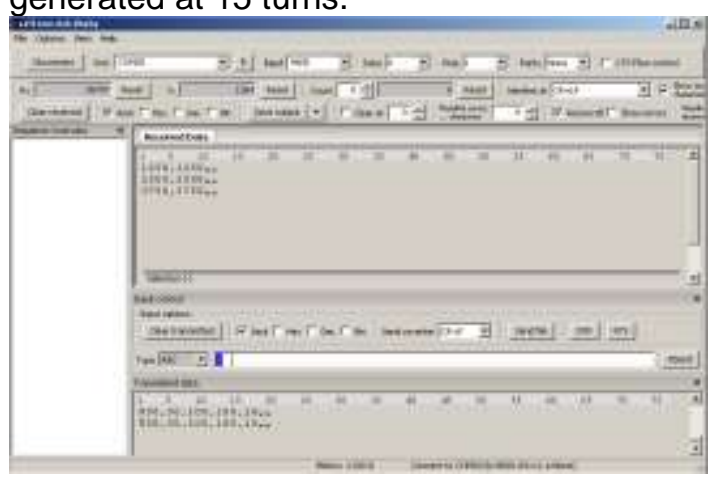

Figure 4.21 Results of Pulse Measurement at 15 Cycles

(Source: Self-processed Results)

The results of testing the distance traveled by the number of wheel rotations given are presented in Figure 4. 21. In Figure 4. 22 is to explain the initial position of the tank and the final position of the tank after moving with 15 rounds of the right wheel and left wheel.

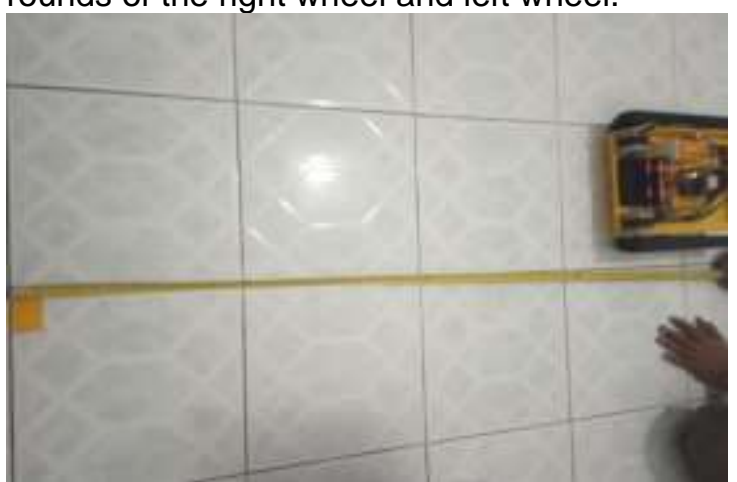

Figure 4.22 Figure Prototype Tank in Final Position

(Source: Self-processed Results)

From the measurement results obtained, the result of measuring distance of $99 \mathrm{~cm}$ and the number of pulses needed to reach a distance of $99 \mathrm{~cm}$ is 3750 pulses. In this test, if it is included in the formula for calculating the pulse to mileage ratio, the results of the comparison are as follows.

$$
\begin{aligned}
\text { pulsa per } \mathrm{cm} & =\frac{\text { pulsa }}{\text { jarakukur }} \\
\text { pulsa per } \mathrm{cm} & =\frac{3750}{99} \\
\text { pulsa per } \mathrm{cm} & =37.87 \mathrm{pulsa} / \mathrm{cm}
\end{aligned}
$$

The fourth test the author gave the command 20 rounds of the right wheel and left wheel. In Figure 4.23 the following is the result of measuring the number of pulses generated at 20 cycles.

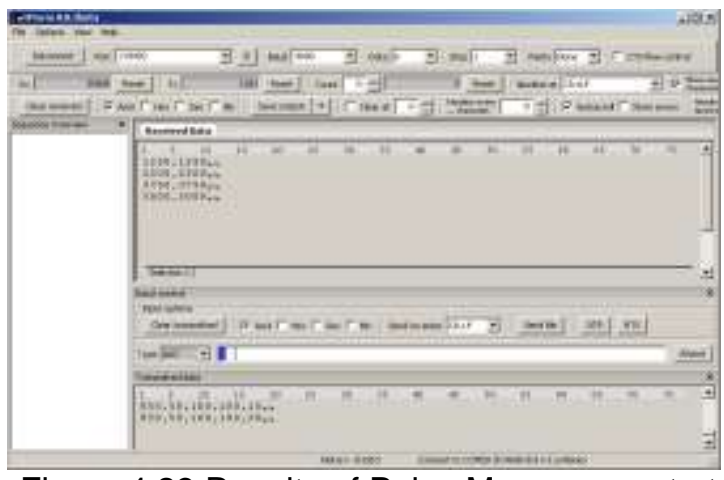

Figure 4.23 Results of Pulse Measurement at 20 Cycles

(Source: Self-processed Results)

The results of testing the distance traveled by the number of wheel rotations given are presented in Figure 4. 24 . In Figure 4. 24 is to explain the initial position of the tank and the final position of the tank after moving with 20 rounds of the right wheel and left wheel. 


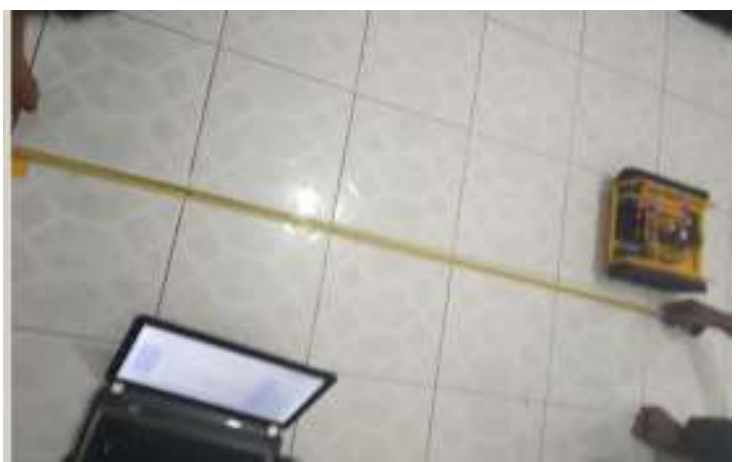

Figure 4.24 Figure of Prototype Tank in Final Position

(Source: Self-processed Results)

From the measurement results obtained by measuring $133 \mathrm{~cm}$ distance and the number of pulses needed to reach a distance of $133 \mathrm{~cm}$ is $\mathbf{5 0 0 0}$ pulses. In this test, if it is included in the formula for calculating the pulse to mileage ratio, the results of the comparison are as follows

$$
\begin{aligned}
\text { pulsa per } \mathrm{cm} & =\frac{\text { pulsa }}{\text { jarakukur }} \\
\text { pulsa per } \mathrm{cm} & =\frac{5000}{133} \\
\text { pulsa per } \mathrm{cm} & =37.59 \text { pulsa } / \mathrm{cm}
\end{aligned}
$$

The fourth test the author gave the command 25 rounds of the right wheel and left wheel. In Figure 4. 25 the following is the result of measurement of the number of pulses generated at 25 turns.

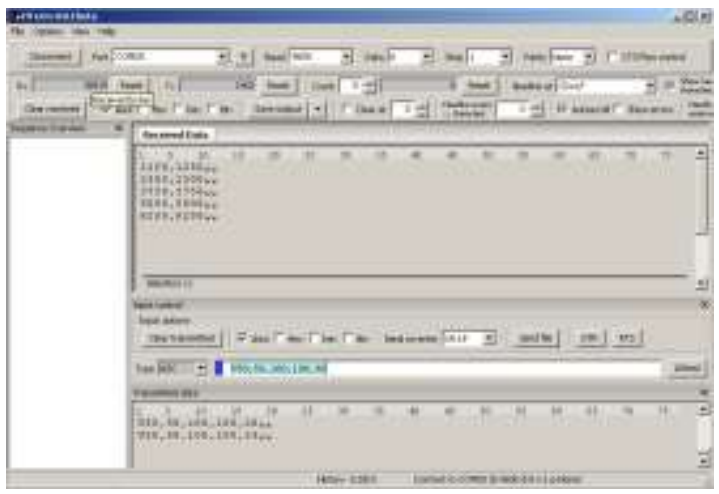

Figure 4.25 Pulse Measurement at 25 Cycles (Source: Self-processed Results)

The results of testing the distance traveled by the number of wheel rotations given are presented in Figure 4. 26 . In Figure 4. 26 is an explanation of the starting position of the tank and the final position of the tank after moving with 25 rounds of the right wheel and left wheel.

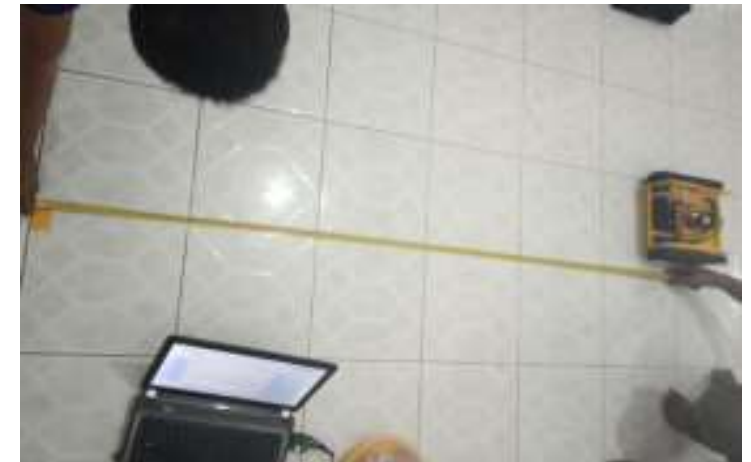

Figure 4.26 Prototype Tank in Final Position (Source: Self-processed Results)

From the measurement results obtained, the results of measuring distance of $168 \mathrm{~cm}$ and the number of pulses needed to reach a distance of $168 \mathrm{~cm}$ is 6250 pulses. In this test, if it is included in the formula for calculating the pulse to mileage ratio, the results of the comparison are as follows

$$
\begin{aligned}
\text { pulsa per } \mathrm{cm} & =\frac{\text { pulsa }}{\text { jarakukur }} \\
\text { pulsa per } \mathrm{cm} & =\frac{6250}{168} \\
\text { pulsa per } \mathrm{cm} & =37.2 \mathrm{pulsa} / \mathrm{cm}
\end{aligned}
$$

The fifth test the author gave orders 30 rounds of right wheel and left wheel. In Figure 4. 27 the following are the results of measurements of the number of pulses generated at 30 cycles.

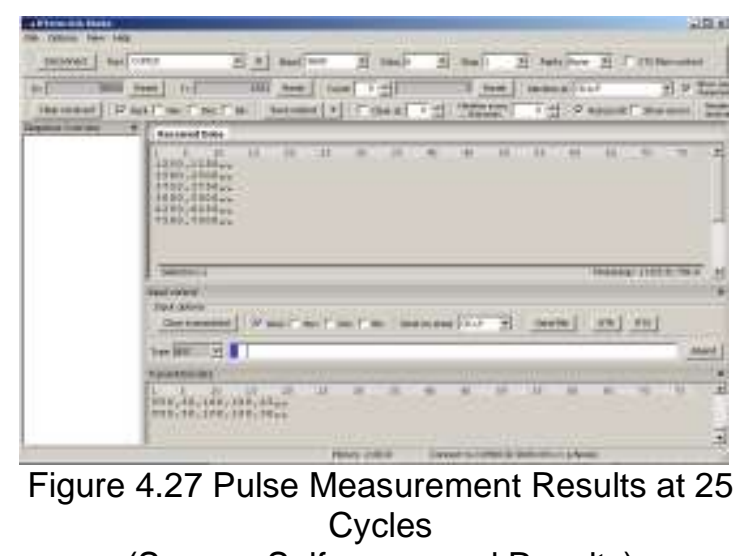

(Source: Self-processed Results)

The results of testing the distance traveled by the number of wheel rotations given are presented in Figure 4. 28 . In Figure 4. 28 is to explain the initial position of the tank and the final position of the tank after moving with 30 rounds of the right wheel and left wheel. 


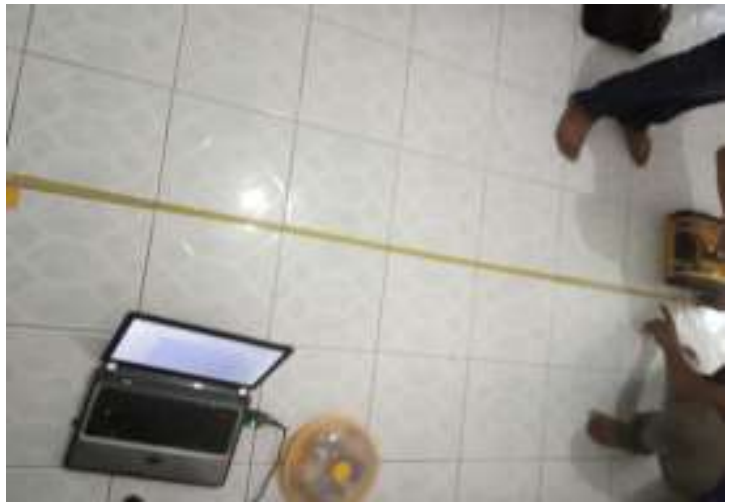

Figure 4.28 Figure of Prototype Tank in Final Position

(Source: Self-processed Results)

From the measurement results obtained, measurements of distance traveled by $198 \mathrm{~cm}$ and the number of pulses needed to reach a distance of $198 \mathrm{~cm}$ is 7500 pulses. In this test, if it is included in the formula for calculating the pulse to mileage ratio, the results of the comparison are as follows

$$
\begin{aligned}
\text { pulsa per } \mathrm{cm} & =\frac{\text { pulsa }}{\text { jarak ukur }} \\
\text { pulsa per } \mathrm{cm} & =\frac{7500}{198} \\
\text { pulsa per } \mathrm{cm} & =37.87 \mathrm{pulsa} / \mathrm{cm}
\end{aligned}
$$

Testing the six authors give 35 commands the right wheel and left wheel. In Figure 4.29 the following is the result of measuring the number of pulses generated at 35 cycles.

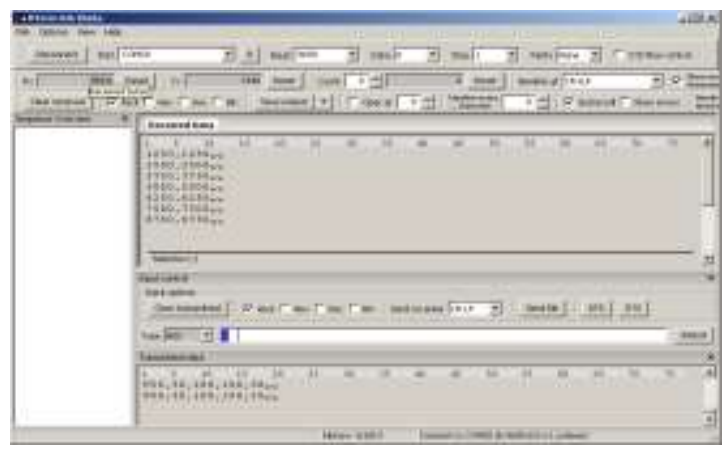

Figure 4.29 Results of Pulse Measurements at 35 Cycles

(Source: Self-processed Results)

The results of testing the distance traveled by the number of wheel rotations given are presented in Figure 4. 30. In Figure 4. 30 is to explain the initial position of the tank and the final position of the tank after moving with 35 rounds of the right wheel and left wheel.

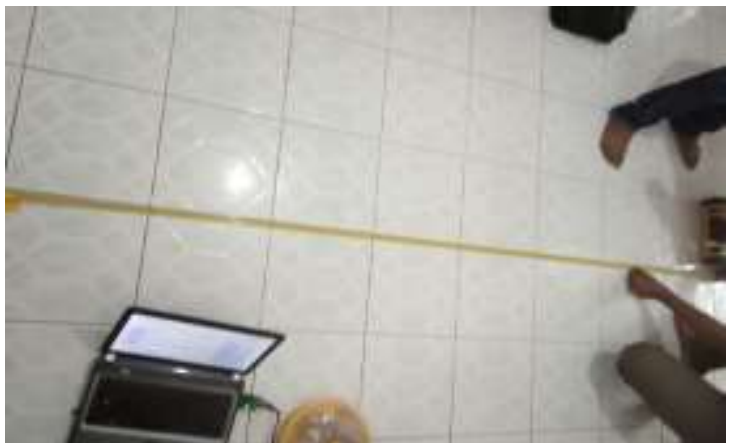

Figure 4.30 Figure of Prototype Tank in Final Position

(Source: Self-processed Results)

From the measurement results obtained, the results of distance measurements of 230 $\mathrm{cm}$ and the number of pulses needed to reach a distance of $230 \mathrm{~cm}$ is 8750 pulses. In this test, if it is included in the formula for calculating the pulse to mileage ratio, the results of the comparison are as follows

$$
\begin{aligned}
\text { pulsa per } \mathrm{cm} & =\frac{\text { pulsa }}{\text { jarak ukur }} \\
\text { pulsa per } \mathrm{cm} & =\frac{8750}{230} \\
\text { pulsa per } \mathrm{cm} & =38.04 \mathrm{pulsa} / \mathrm{cm}
\end{aligned}
$$

Testing the seven authors give the order of 40 rounds of the right wheel and left wheel. In Figure 4.31 the following is the result of measurement of the number of pulses generated at 40 turns.

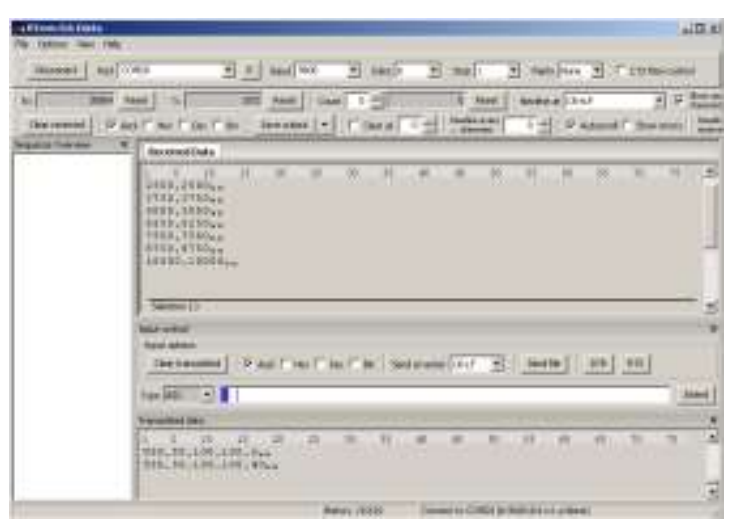

Figure 4.31 Results of Pulse Measurements at 40 Cycles

(Source: Self-processed Results)

The results of testing the distance traveled by the number of wheel rotations given are presented in Figure 4. 32 . In Figure 4. 32 is to explain the initial position of the tank and the final position of the tank after moving with 40 rounds of the right wheel and left wheel. 


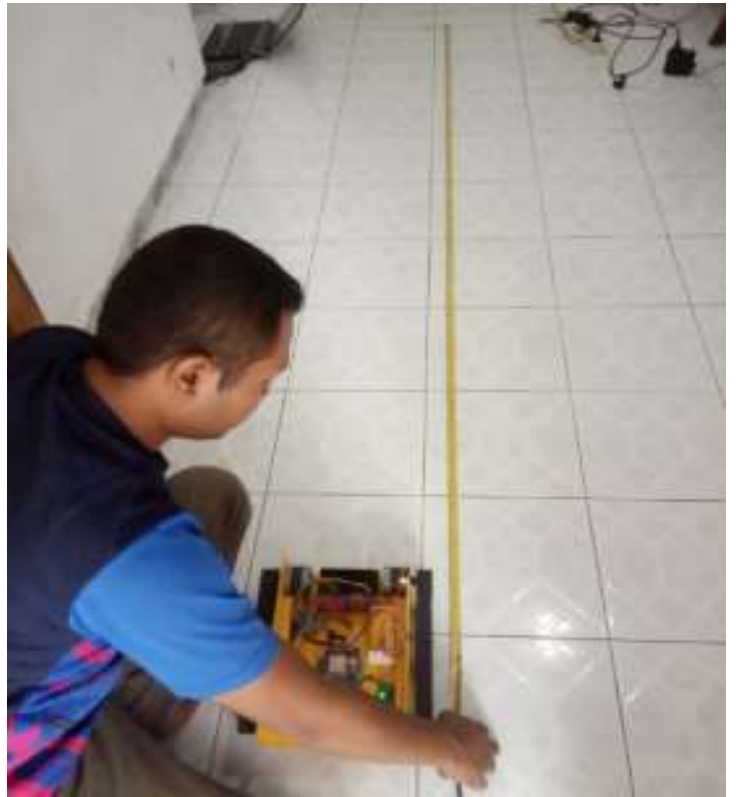

Figure 4.32 Figure of Prototype Tank in Final Position

(Source: Self-processed Results)

From the results of measurements made obtained by measuring distance of $260 \mathrm{~cm}$ and the number of pulses needed to reach a distance of $260 \mathrm{~cm}$ is 10000 pulses. In this test, if it is included in the formula for calculating the pulse to mileage ratio, the results of the comparison are as follows

$$
\begin{aligned}
\text { pulsa per } \mathrm{cm} & =\frac{\text { pulsa }}{\text { jarak ukur }} \\
\text { pulsa per } \mathrm{cm} & =\frac{10000}{260} \\
\text { pulsa per } \mathrm{cm} & =38.46 \mathrm{pulsa} / \mathrm{cm}
\end{aligned}
$$

Testing the eight writers give the order of 45 rounds of the right wheel and left wheel. In Figure 4.33 the following is the result of measurement of the number of pulses generated at 45 turns.

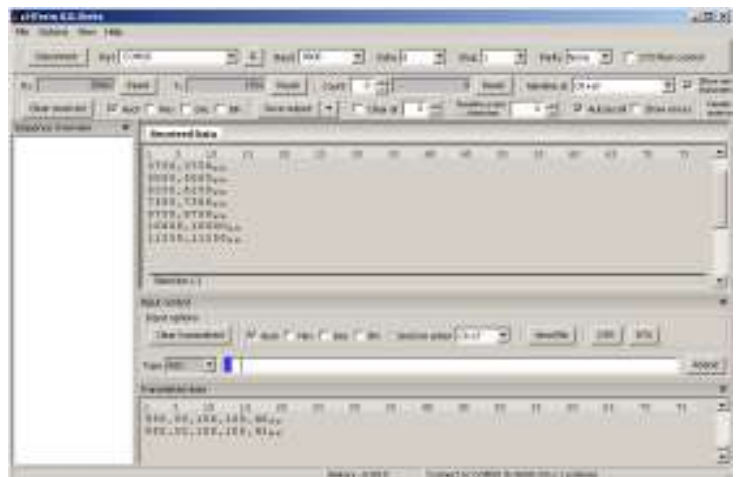

Figure 4.33 Results of Pulse Measurement at 45 Cycles

(Source: Self-processed Results)
The results of testing the distance traveled by the number of wheel rotations given are presented in Figure 4. 34 . In Figure 4. 34 is to explain the initial position of the tank and the final position of the tank after moving with 45 rounds of the right wheel and left wheel.

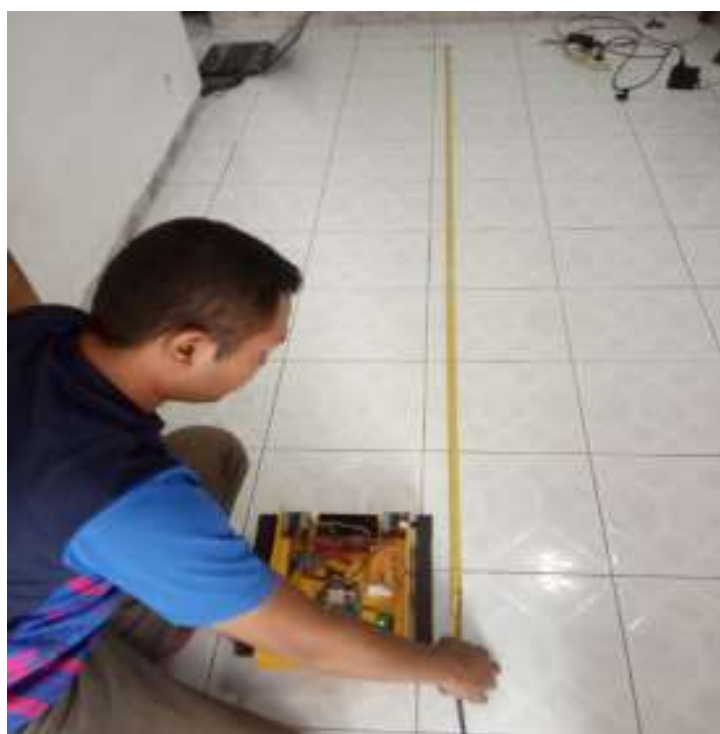

Figure 4.34 Figure of Prototype Tank in Final Position

(Source: Self-processed Results)

From the results of measurements made obtained by measuring distance of $290 \mathrm{~cm}$ and the number of pulses needed to reach a distance of $290 \mathrm{~cm}$ is 11250 pulses. In this test, if it is included in the formula for calculating the pulse to mileage ratio, the results of the comparison are as follows

$$
\begin{aligned}
\text { pulsa per } \mathrm{cm} & =\frac{\text { pulsa }}{\text { jarak ukur }} \\
\text { pulsa per } \mathrm{cm} & =\frac{11250}{290} \\
\text { pulsa per } \mathrm{cm} & =38.79 \mathrm{pulsa} / \mathrm{cm}
\end{aligned}
$$

Testing the nine authors give 50 orders of rotation of the right wheel and left wheel. In Figure 4.35 the following is the result of measuring the number of pulses generated at 50 turns. 


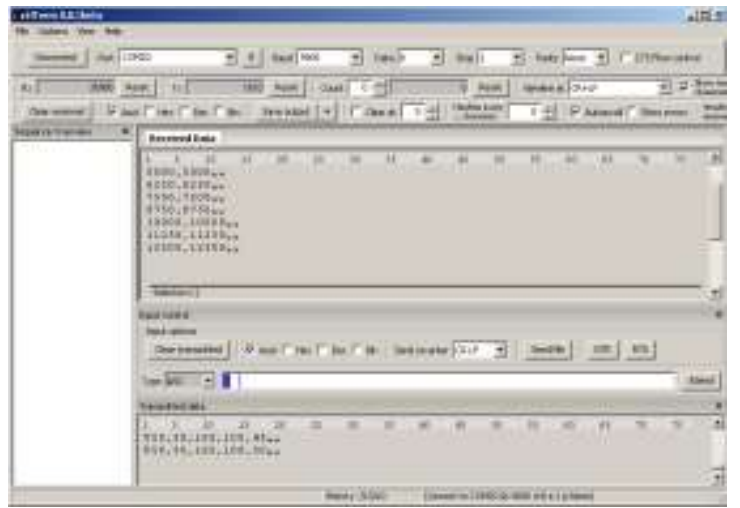

Figure 4.35 Results of Pulse Measurement at 50 Cycles

(Source: Self-processed Results)

The results of testing the distance traveled by the number of wheel rotations given are presented in Figure 4. 36. In Figure 4. 36 is to explain the initial position of the tank and the final position of the tank after moving with 50 rounds of the right wheel and left wheel.

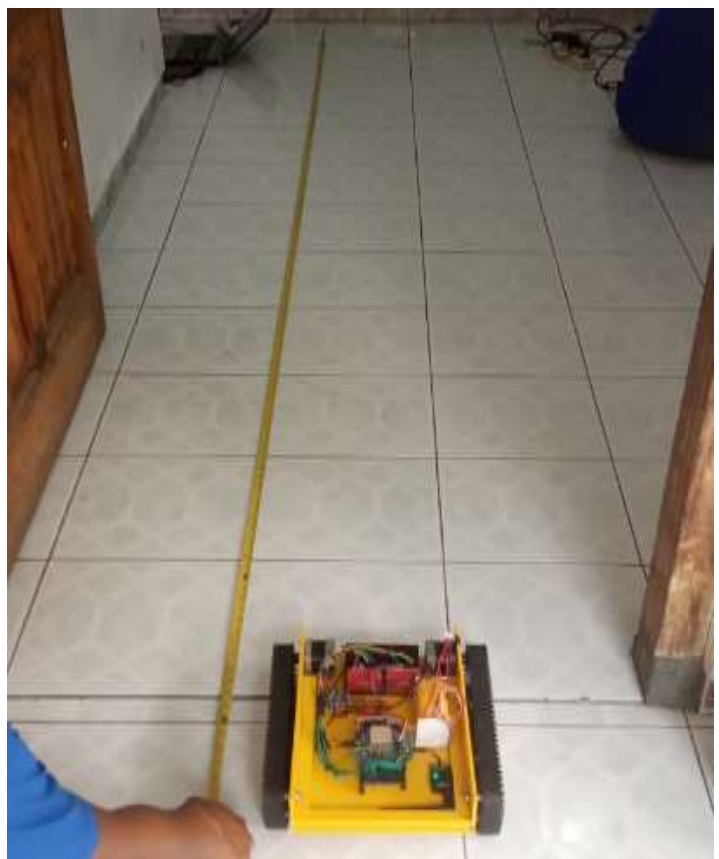

Figure 4.36 Figure of Prototype Tank in Final Position

(Source: Self-processed Results)

From the measurement results obtained, the measurement results for the distance of 328 $\mathrm{cm}$ and the number of pulses needed to reach a distance of $328 \mathrm{~cm}$ is 12500 pulses. In this test, if it is included in the formula for calculating the pulse to mileage ratio, the results of the comparison are as follows.

$$
\begin{aligned}
\text { pulsa per } \mathrm{cm} & =\frac{\text { pulsa }}{\text { jarakukur }} \\
\text { pulsa per } \mathrm{cm} & =\frac{12500}{328} \\
\text { pulsa per } \mathrm{cm} & =38.1 \text { pulsa } / \mathrm{cm}
\end{aligned}
$$

The following results of measurements and calculations of distance measurements in the form of distance measurement tables. In the Distance Measurement Table, the calculation value is obtained to get the number of pulses per $\mathrm{cm}$.

Table 4. 1 PrototypeTank Mechanism Measuring Distance Forward Forward Measurement Table

(Source: Self-processed Results)

\begin{tabular}{|c|c|c|c|}
\hline No & Pulsa & Jarak(cm) & Pulsa/cm \\
\hline 1 & 1250 & 32 & 39.06 \\
\hline 2 & 2500 & 65 & 38.46 \\
\hline 3 & 3750 & 99 & 37.88 \\
\hline 4 & 5000 & 133 & 37.59 \\
\hline 5 & 6250 & 168 & 37.20 \\
\hline 6 & 7500 & 198 & 37.88 \\
\hline 7 & 8750 & 230 & 38.04 \\
\hline 8 & 10000 & 260 & 38.46 \\
\hline 9 & 11250 & 290 & 38.79 \\
\hline 10 & 12500 & 328 & 38.11 \\
\cline { 3 - 4 } & & Rata-rata & 38.15 \\
\cline { 3 - 4 }
\end{tabular}

From the Measurement Table 4.1, a graph can be made to get the value of pulse conversion per $\mathrm{cm}$, based on 10 results of tests that have been done.

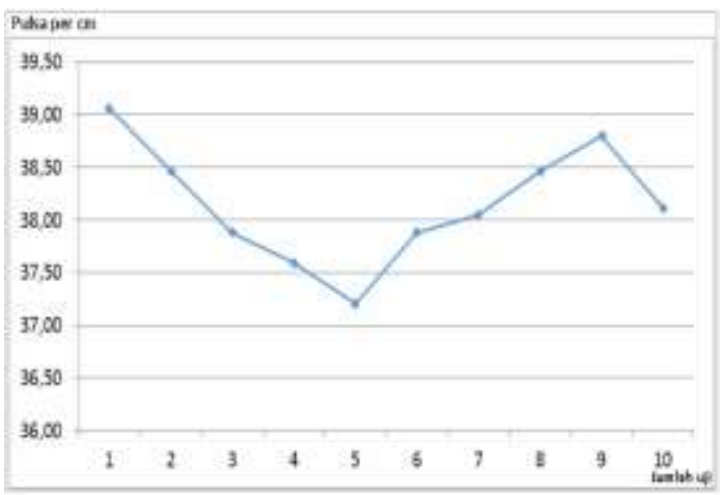

Figure 4.37 Graph of Credit Value Per cm

(Source: Self-processed Results)

Testing the ten authors give the order of 5 rounds of the right wheel and the left wheel backwards. Figure 4. 38 The following is the result of many measurements of the pulses generated in the fifth round. 


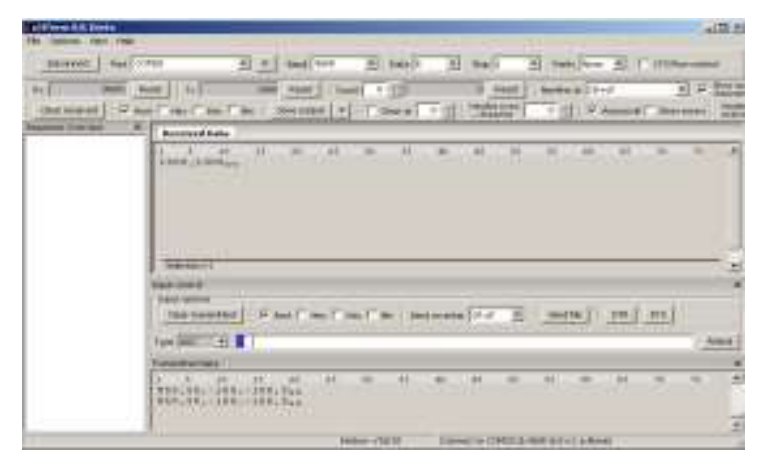

Figure 4.38 Results of Pulse Measures at 5 Reverse Rotations

(Source: Self-processed Results)

The results of testing the distance traveled by the number of wheel rotations given are presented in Figure 4. 39. At the $G$ amber 4. 39 is explained starting position and end position tanks tank after moving to fifth wheel rotation right and left wheels.

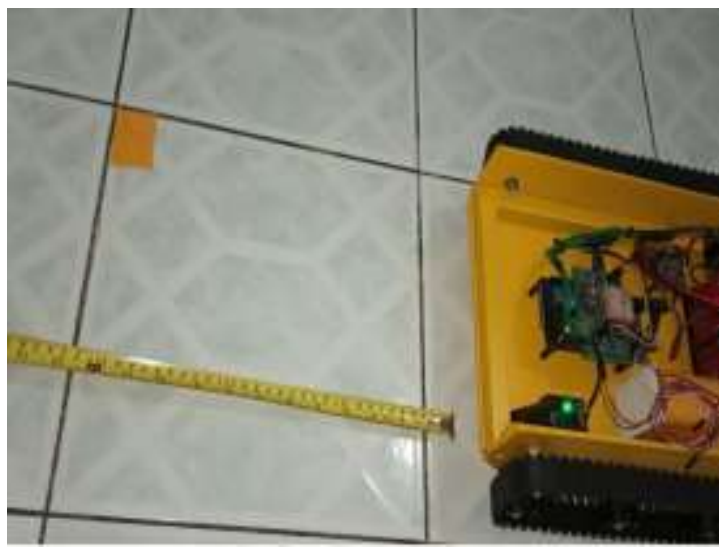

Figure 4.39 Figure of Prototype Tank in Final Position

(Source: Self-processed Results)

From the measurement results obtained, the measurement of the distance traveled by $32.5 \mathrm{~cm}$ and the number of pulses needed to reach a distance of $32.5 \mathrm{~cm}$ is 1000 pulses. In this test, if it is included in the formula for calculating the pulse to mileage ratio, the results of the comparison are as follows

$$
\begin{aligned}
\text { pulsa per } \mathrm{cm} & =\frac{\text { pulsa }}{\text { jarak ukur }} \\
\text { pulsa per } \mathrm{cm} & =\frac{1000}{32.5} \\
\text { pulsa per } \mathrm{cm} & =30.77 \mathrm{pulsa} / \mathrm{cm}
\end{aligned}
$$

The eleventh test gives the order 10 rounds of the right wheel and the left wheel backward. Figure 4. 40 The following is the result of many measurements of the pulses generated at 10 rounds.

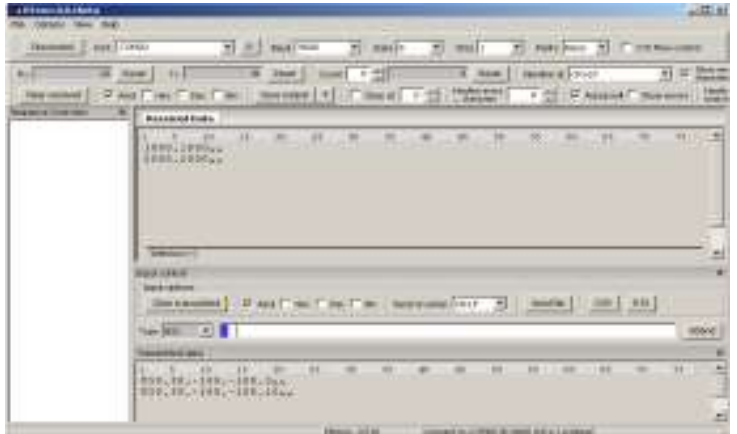

Figure 4.40 Results of Pulse Measures at 10 Reverse Rotations

(Source: Self-processed Results)

The results of testing the distance traveled by the number of wheel rotations given are presented in Figure 4.4 1. Figure 4.41 is an explanation of the starting position of the tank and the final position of the tank after moving with 10 rounds of the right and left wheels.

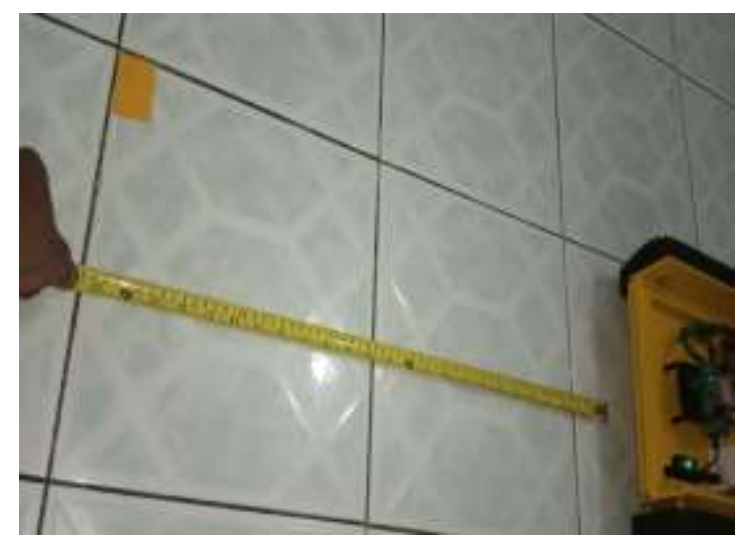

Figure 4.41 Figure of Prototype Tank in Final Position

(Source: Self-processed Results)

From the measurement results obtained, the results of measuring distance of $65 \mathrm{~cm}$ and the number of pulses needed to reach a distance of $65 \mathrm{~cm}$ is 2000 pulses. In this test, if it is included in the formula for calculating the pulse to mileage ratio, the results of the comparison are as follows

$$
\begin{aligned}
\text { pulsa per } \mathrm{cm} & =\frac{\text { pulsa }}{\text { jarak ukur }} \\
\text { pulsa per } \mathrm{cm} & =\frac{2000}{65} \\
\text { pulsa per } \mathrm{cm} & =30.76 \text { pulsa } / \mathrm{cm}
\end{aligned}
$$

The twelfth test gives the order 15 rightwheel rotation and left-wheel backward motion. In Figure 4. 42 the following are the results of measurements of the number of pulses generated at 15 turns. 


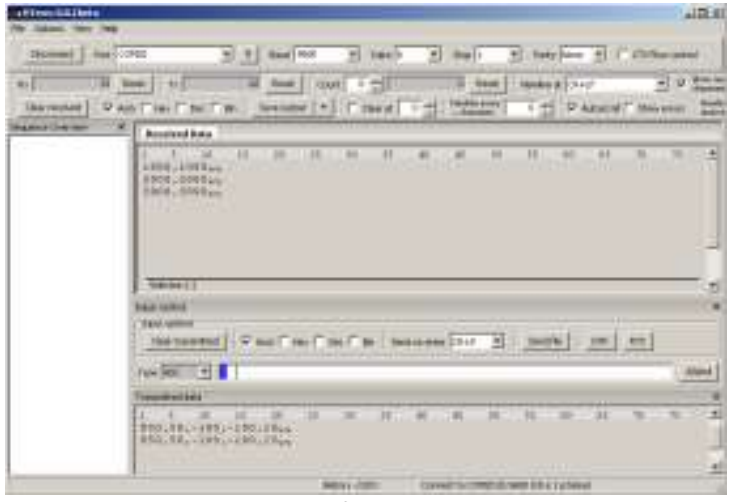

Figure 4.42 Results of Pulse Measurements at 15 Reverse Steps

(Source: Self-processed Results)

The results of testing the distance traveled by the number of wheel rotations given are presented in Figure 4. 43 . In Figure 4.43 is to explain the initial position of the tank and the final position of the tank after moving with 15 rounds of the right wheel and left wheel.

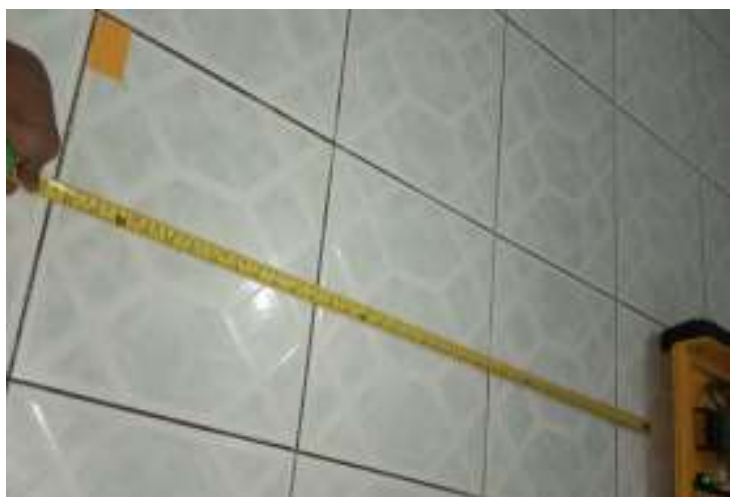

Figure 4.43 Figure of Prototype Tank in Final Position

(Source: Self-processed Results)

From the measurement results obtained, the measurement of distance traveled by $98 \mathrm{~cm}$ and the number of pulses needed to reach a distance of $98 \mathrm{~cm}$ is 3000 pulses. In this test, if it is included in the formula for calculating the pulse to mileage ratio, the results of the comparison are as follows

$$
\begin{aligned}
\text { pulsa per } \mathrm{cm} & =\frac{\text { pulsa }}{\text { jarak ukur }} \\
\text { pulsa per } \mathrm{cm} & =\frac{3000}{98} \\
\text { pulsa per } \mathrm{cm} & =30.61 \mathrm{pulsa} / \mathrm{cm}
\end{aligned}
$$

The thirteenth test gives the order of 20 right wheel and left wheel reverse. In Figure 4. 44 the following is the result of measurement of the number of pulses generated at 20 cycles.

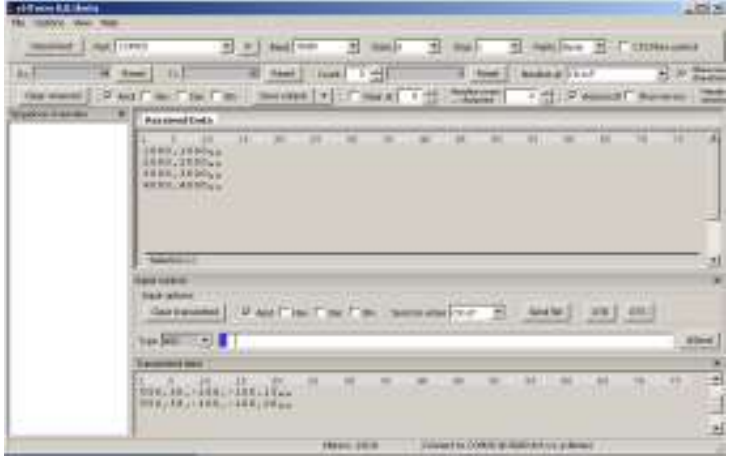

Figure 4.44 Results of Pulse Measurements at 20 Reverse Steps

(Source: Self-processed Results)

The results of testing the distance traveled by the number of wheel rotations given are presented in Figure 4. 45 In Figure 4.45 is describing the initial position of the tank and the final position of the tank after moving with 20 rounds of right and left wheels.

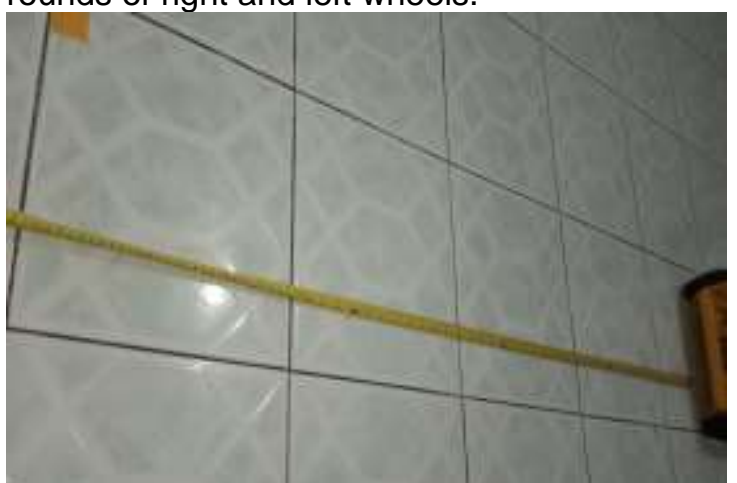

Figure 4.45 Figure of Prototype Tank in Final Position

(Source: Self-processed Results)

From the measurement results obtained by measuring the distance of $131 \mathrm{~cm}$ and the number of pulses needed to reach a distance of $131 \mathrm{~cm}$ is 4000 pulses. In this test, if it is included in the formula for calculating the pulse to mileage ratio, the results of the comparison are as follows

$$
\begin{aligned}
\text { pulsa per } \mathrm{cm} & =\frac{\text { pulsa }}{\text { jarak ukur }} \\
\text { pulsa per } \mathrm{cm} & =\frac{4000}{131} \\
\text { pulsa per } \mathrm{cm} & =30.53 \text { pulsa } / \mathrm{cm}
\end{aligned}
$$

Here are the results of measurements and calculations of distance measurements in the form of a Backward Distance Measurement Table. In the distance measurement table, the calculation value is obtained to get the number of pulses per $\mathrm{cm}$. 
Table 4. 2 Table of Measures of Backward Distance of the Mechanism PrototypeTank

(Source: Self-processed Results)

\begin{tabular}{|c|c|c|c|}
\hline No & Pulse & $\begin{array}{c}\text { Distance } \\
\text { (cm) }\end{array}$ & Credit/cm \\
\hline 1 & 1000 & 32.5 & 30.77 \\
\hline 2 & 2000 & 65 & 30.77 \\
\hline 3 & 3000 & 98 & 30.61 \\
\hline 4 & 4000 & 131 & 30.53 \\
\hline & & Average & 30.67 \\
\hline
\end{tabular}

From the Measurement Table 4.2 a Graph can be made to obtain the value of pulse conversion per $\mathrm{cm}$, based on 4 results of backward motion tests that have been carried out.

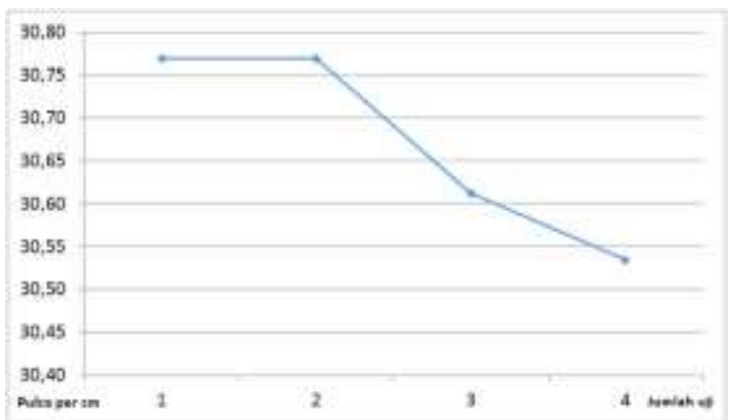

Figure 4.46 Graph of Credit Value Per cm (Source: Self-processed Results)

coordinates are stored in the database server .

\section{CONCLUSIONS AND SUGGESTIONS}

\subsection{Conclusions}

The conclusions obtained based on the Design of Mechanisms and Motion Systems in Prototype Tanks Using Odometry that have been made, can be mentioned, namely:

a. Based on the results of the design and testing of the prototype tank motion system, a design of the motion drive system is obtained using 2 stepper motors applied to a tank prototype

b. The application of Odometry to the prototype tank, based on the results of tests that have been carried out can be applied to calculate the displacement of the prototype tank's position with an error value to the actual distance obtained an error value of less than $1 \%$

\subsection{Suggestions}

Based on the research results of the Design of Mechanisms and Motion Systems in Prototype Tanks Using Odometry that has been done by the author, it can be given suggestions for further system development. These suggestions can be explained as follows:

a. Develop a drive mechanism with a higher rotational capability, this is related to the final result of increased speed of movement.

b. Developing a driving mechanism with a higher torque, this is related to the ability of the prototype tank asphalt in difficult terrain.

Suggestions in this development aim to improve the ability to move, so as to improve the ability to roam prototype tanks in difficult terrain or areas.

\section{ACKNOWLEDGEMENT}

The authors greatly acknowledge the support from Naval Technology College, STTAL Surabaya Indonesia for providing the necessary resources to carry out this research work. The authors are also grateful to the anonymous reviewers and journal editorial board for their many insightful comments, which have significantly improved this article.

\section{REFERENCES}

Andalas. Hidayat, Anton. 2014. DC motor. Teaching Material for Robotics. Andalas University.

Andrianto Heri, 2008, AVR ATMEGA16 Microcontroller Programming,

Informatics, Bandung.

Bejo Agus, 2008, C and AVR Secret of the Ease of Language $C$ in

ATMega8535 microcontroller, first edition, Graha Ilmu, Yogyakarta.

Dermanto Trikueni, 2013, The reversal of the direction of the dc motor, http: // trikuenisystem

design. blogspot.com/2013/10/Replaceturn-motor-DC-seri.html accessed on 4 July 2019.

Eitel, Elisabeth. (2014), Basic Rotary Encoder: Overview and New Technologies, 
http://machinedesign.com/sensors/basi cs-rotary-encoders-overview-andnewtechnologies-0.

Fahmizal, 2011, Permanent magnet dc motor, http: // fahmizaleeits.

wordpress.com/2011/12/04/drivermotor-dc-padarobot-beroda-withconfiguration-h-bridge-mosfet/ accessed on June 16, 2019.

lja Sembiring, 2009, DC motor speed regulation,

http://repository.usu.ac.id/bitstream/123 456789/11857/1/09E00078.pdf, accessed on June 24, 2010.

Hidayat, Anton. 2014. DC motor. Teaching Material for Robotics. University

Mohammad Nasucha 2015, Development Of An Obstacle Avoiding Robot, Jaya Development University.

M Ashish 2018, Automated Hybrid Surveillance Robots

Mech, Hades. (2010), Rotary Encoder, http://hades.mech.northwestern.edu/ind ex.php/Rotary_Encoder.

Mechatronicscrew. (2014), Introduction to Microcontrollers,

https://mechatronicscrew.wordpress.co $\mathrm{m} /$ praktikum/practicalummechatronics/ mikrokontroler/

Nasution Fadli, 2012, Motor Driver L298,

http://ini-

robot.blogspot.com/2012/06/drivermotor-l298-2a-dual-hbridge. html accessed on June 27, 2019.

Pitowarnno, Endra. 2006. Robotics: Design, Control, and Artificial intelligence. Andi offset: Yogyakarta.

Widodo Budiharto 2015, Intelligent Surveillance Robots with Obstacle Avoidance Capabilities Using Neural Networks, School of Computer Science, Bina Nusantara University, Jakarta, Indonesia.

Cahyono, Endro. 2018. Design and Build of Prototype Height Control of the Cakra Class Periscope Submarine Using Arduino to Support Assignments in the Field of Operations. Surabaya. Roger S. Pressman, P. (2002). Software Engineering (Practitioner Approach). Yogyakarta: Andi Publisher.
Kendall $E$ Kenneth and Kendall $E$ Julie. (2006). System Analysis and Design. Bandung: PT. Index.

Jeffrey A. Hoffer, Joey F. George, Joseph S. Valacich. (2012). Modern Systems Analysis and Design (Sixth Edition). New Delhi: Pearson Education.

John Burch and Gary Grudnitski. (1986). Information Systems Theory and Practice. New York: John Wiley and Sons. 